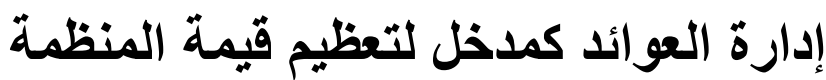

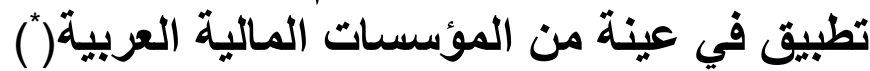

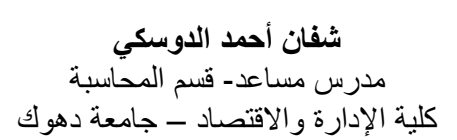

شفان أحمد الدوسكي

كلية الإدارة و الاقتصاد - جامعة دهو كك
الاكتور سرمد كوكب الجميل

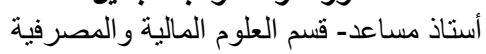

كلية الإدارة والاقتصاد - جامعة الموصل لمكل

Sarmad_aljamil53@yahoo.com

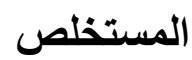

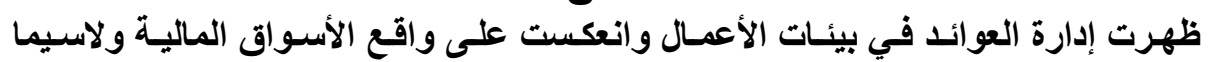

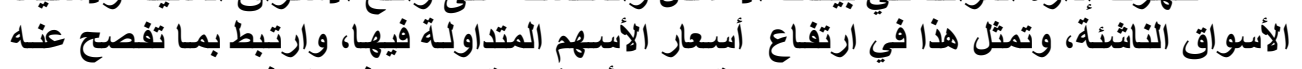

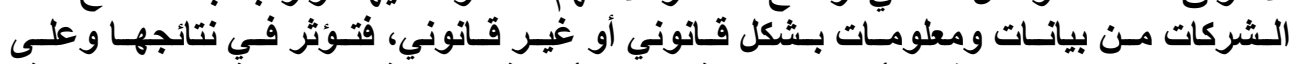

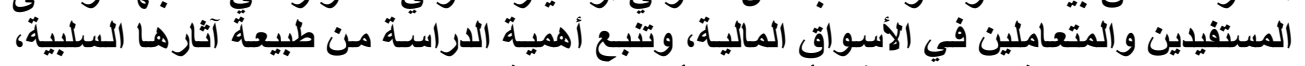

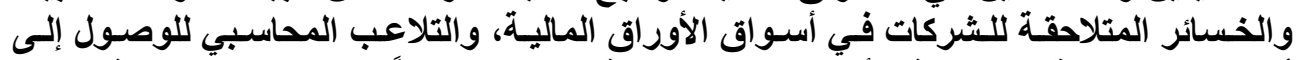

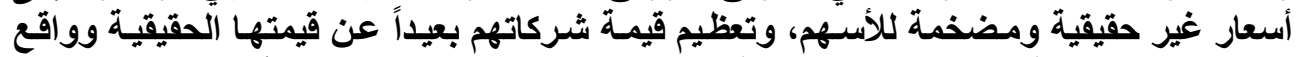

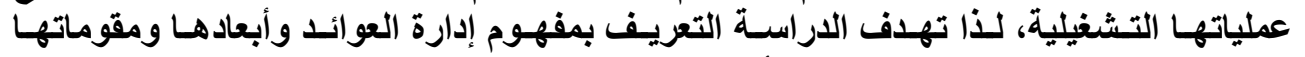

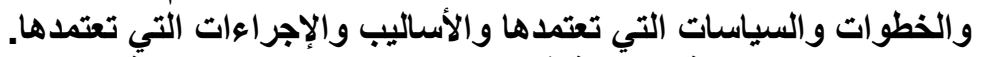

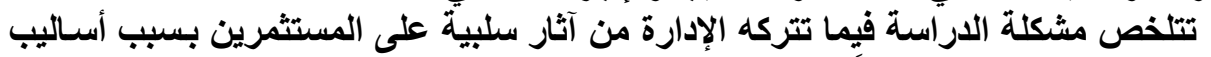

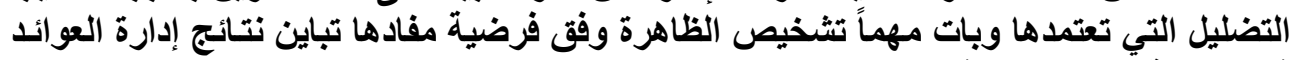

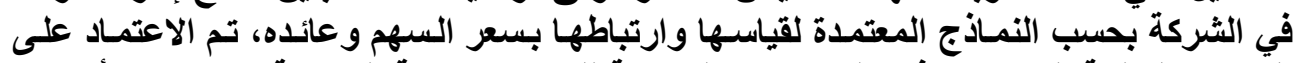

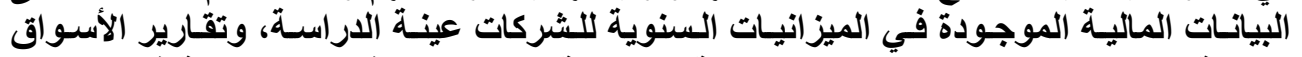

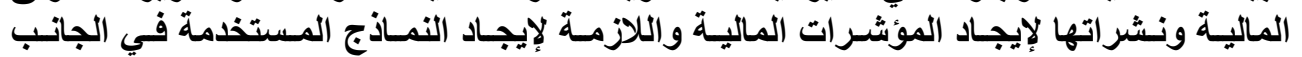

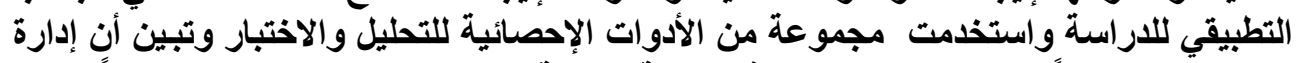

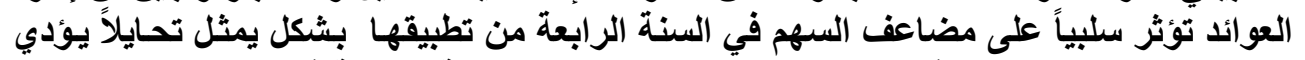
إلى زيادة مضاعف السهم في السوق، ويماً يفسر من تعظيم قيمة الثرة الثركة في السوق.

( ) بحث مستل من رسالة الماجستير الموسومة "إدارة العو ائد كمدل لتعظيم قبمـة المنظمـة"، كليـة الإدارة و الاقتصاد - جامعة الموصل. 


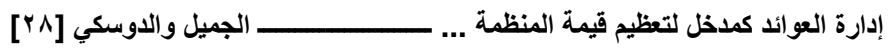

\title{
Earning Management as an Approach to Maximize Value of Organization Applied in a Sample of Arabic Financial Institutes
}

\author{
Sarmad K. Al - Jameel (PhD) \\ Assistant Professor \\ Department of Financial and Banking \\ Sciences \\ University of Mosul
}

\author{
Shifan A. Al - Doski \\ Assistant Lecturer \\ Department of Accountancy \\ University of Duhok
}

\begin{abstract}
Revenues management has been represented in administrative environments. These have been reflected in the situation of financial markets almost in the growing markets. This has been embodied in the increase of stock prices. The data disclosures of several companies correlated legally and illegally, have affected potentially on the participants of the financial markets. The importance of the study has been sparked over the nature of negative effects, successive losses of many financial stock markets, accounting manipulation to reach to unreal prices and inflating stocks, as well as empower the value of companies out of actual principles. The problem of the current paper is subjected to the bases of management negative effects on investors, because of blackout depended. It is important however to diagnose the current phenomenon according to the hypothesis that revenues management in the company may be varied. This variance is caused by stock prices and revenues. The data were depended in the sample companies, financial reports, and financial indicators to see the necessary models in application. Statistical applications were drawn in the analysis of the data. It is concluded that revenues management affects the duplicating stock in the fourth year of application as circumventing process to increase the stock in the market, and interpret the value of company in markets.
\end{abstract}

المقدمة

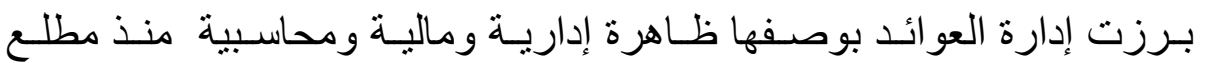

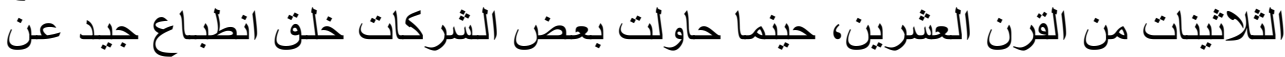

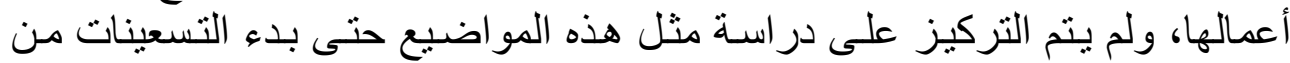

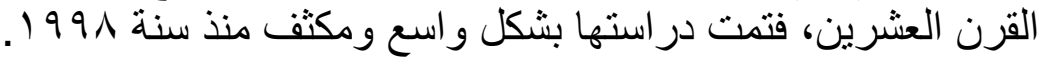

مشكلة الدراسة

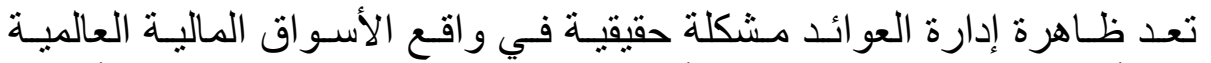

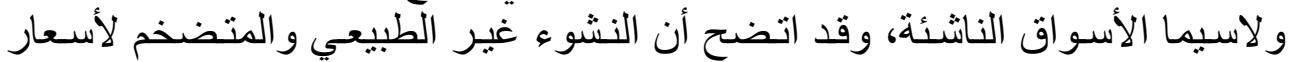

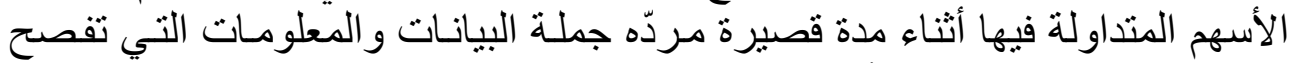

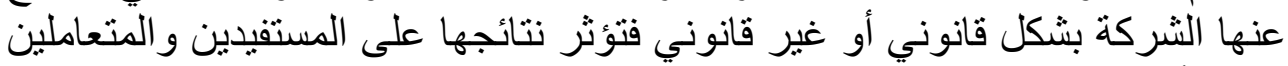

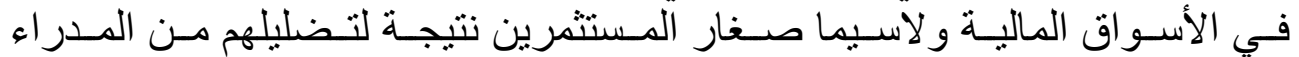
و المسيطرين على المعلومات المالية المتدفقة إلى الأسو اق المالية. 
تنبع أهمية در اسة موضوع إدارة العو ائد من طبيعة آثار هـا السلبية، و انتشار ها أهمية الدراسة

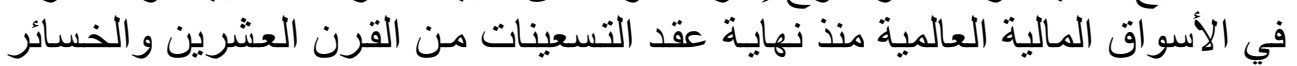

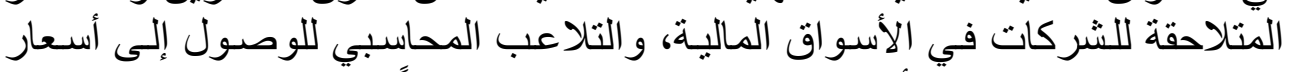

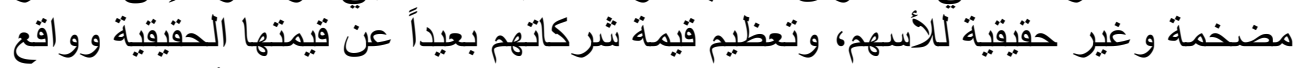

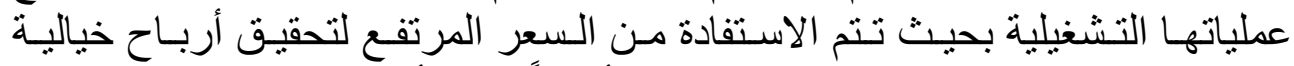

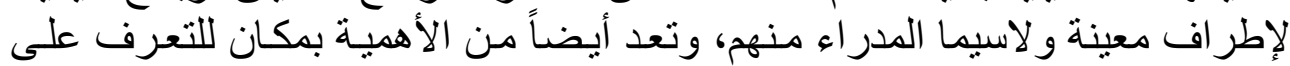

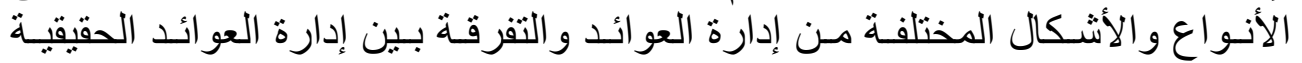

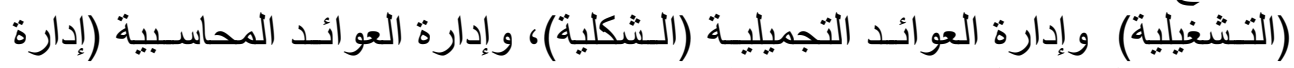
العو ائد بشكل متحايل بعيد عن واقع الثركة الاقتصادي).

\section{أهداف الاراسة}

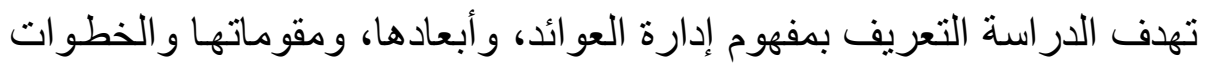

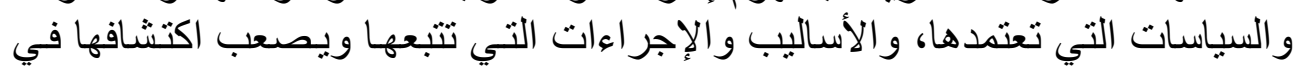

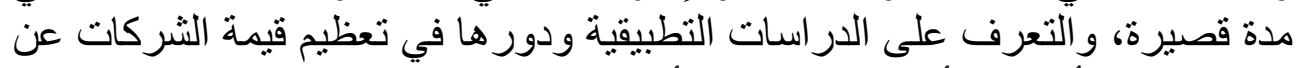

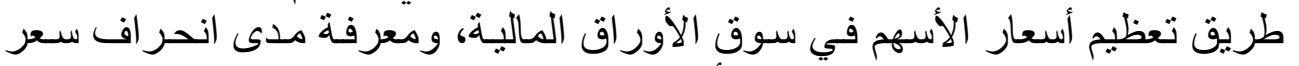

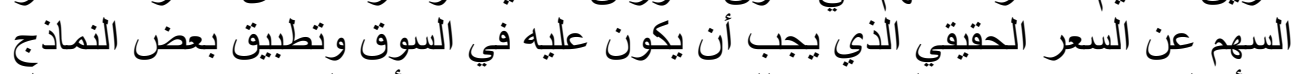

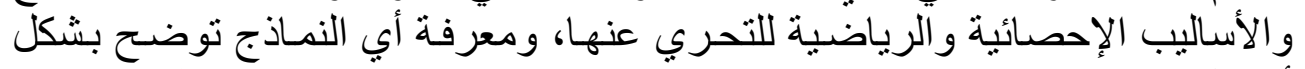

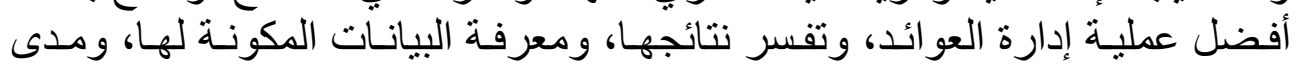

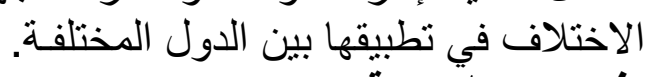

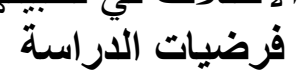

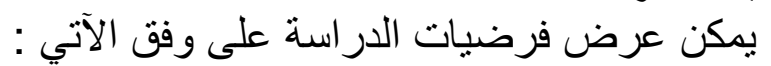

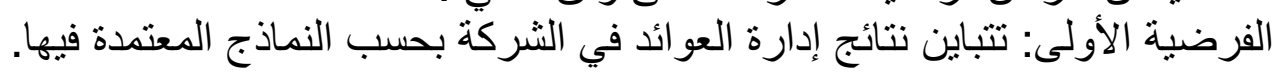

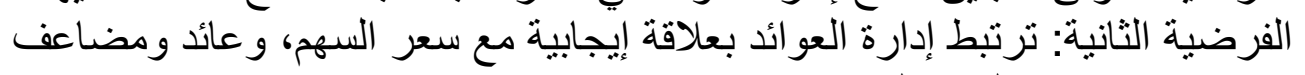

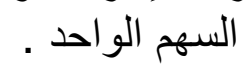

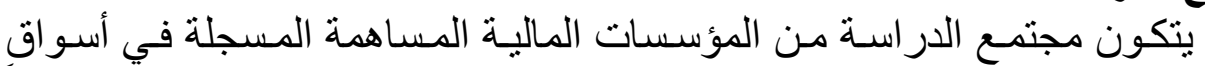

\section{مجتمع الاراسة}

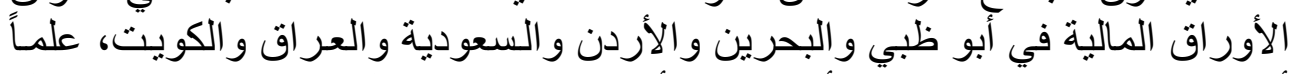

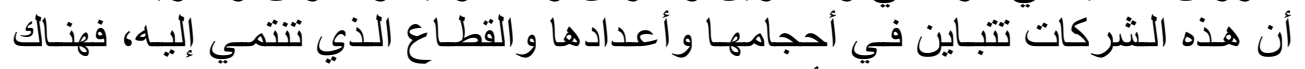

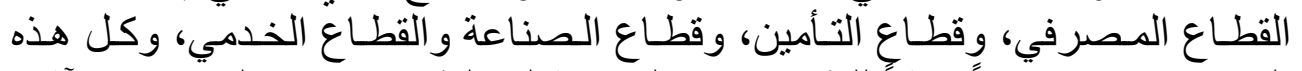

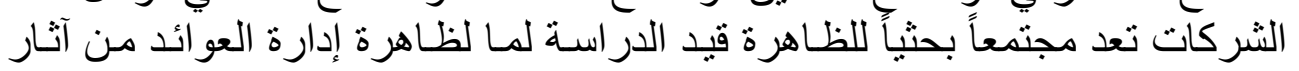

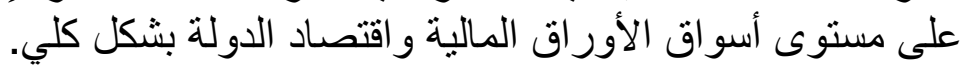




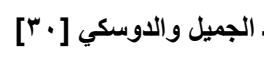
إدارة العوائد كمدخل لتعظيم قيمة المنظمة ...

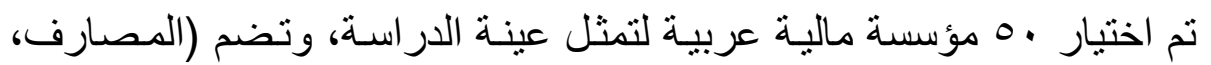

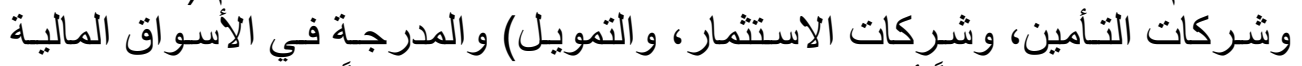
الشمولة بالدراسة علماً أن انتقاء المؤسسات المالية تم عشو ائياً.

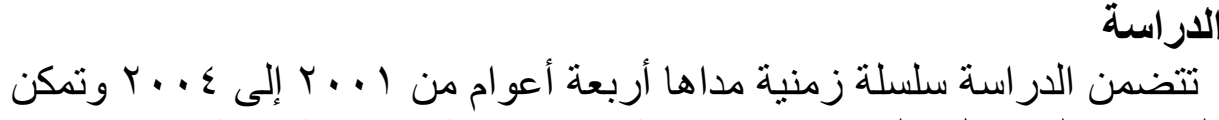
هذه المدة من الحصول على نتائج اقتصادية ذات معنوية إحصائية دقيقة. الحئ.

$$
\text { أساليب جمع البيانات والمعلومات }
$$

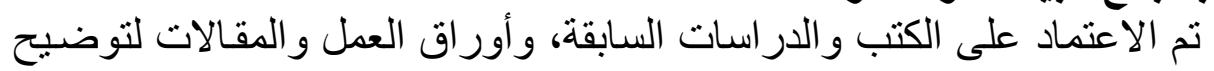

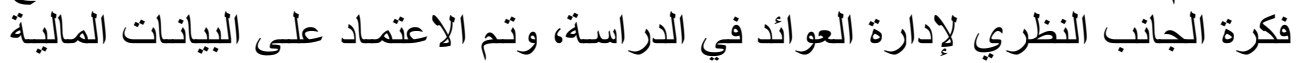

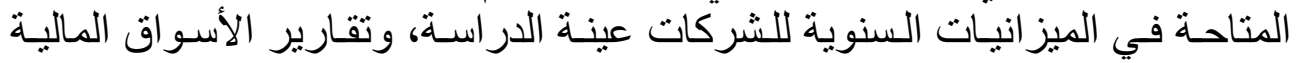

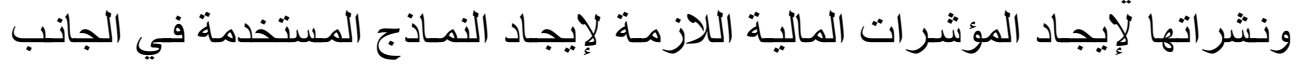
التطبيقي للار اسة.

لاختبار فرضيات الدراسة تم الاعتماد على مجموعة من الأدوات الإحصائية،

$$
\text { أدوات الدراسة }
$$

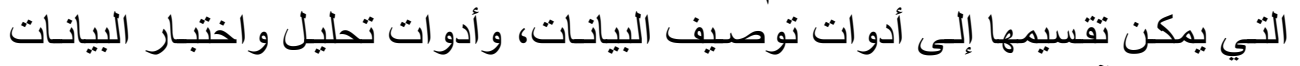

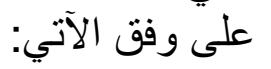

$$
\text { 1 أدوات توصيف البيانات }
$$

• الوسط الحسابي (المتوسط) The Arithmetic Mean (Average) • •

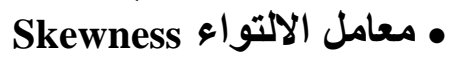

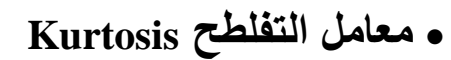
• أعلى / أدنى قُيمة

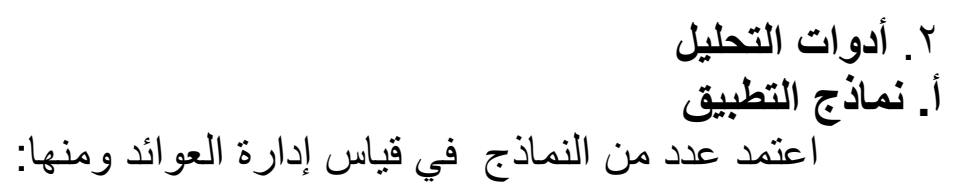

Healy Model : (Zhang, 2002, 9) . 1

يعتمد هذا الأنموذج على نسبة المستحقات غير الاعتيادية (المقدرة) في المدة. وقد تم استخدام الصيغة الآتية:

Expected Discretionary Accruals it $=$ Total Accruals it $/$ Asseti $_{\text {-1 }}$ إذ تمثل المتغير ات على وفق الآتي:

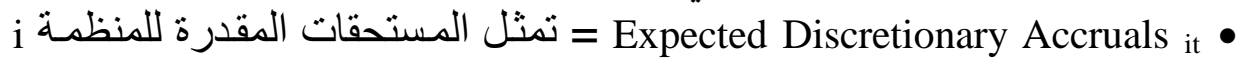

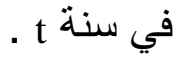


t Total Accruals it

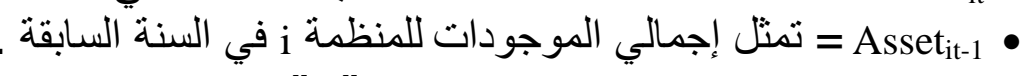
" •" DeAngelo Model: (Ibrahim, 2004, 14) . Y

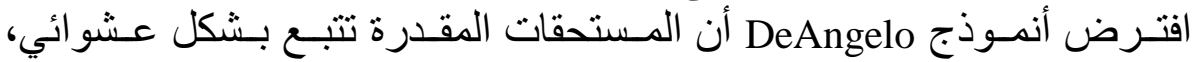

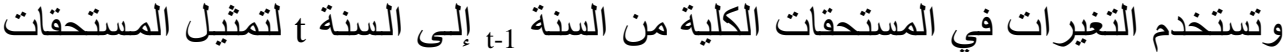
المقدرة، وقد استخدمت الصيغة الآتية:

Expected Discretionary Accruals At $_{i t}=\left(\right.$ Total Accruals At $_{i t}-$ Total Accruals $i_{t-1}$ ) / Asseti $i_{t-1}$

$$
\text { إذ تمثل المتغير ات وفق الآتي: }
$$

i تمثنل المستحقات المقدرة للمنظمـة Expected Discretionary Accruals it

$$
\text { في سنة }
$$

Total Accruals it •

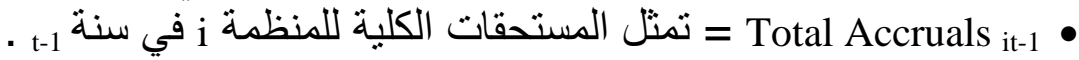
• تمثل إجمالي الموجودات للمنظمة i في السنة السابقة .

Jones Model : (Culvenor, 1998, 4).r

استخدم أنموذج Jones المستحقات غير المقدرة، والتي تمثل المستوى الطبيعي

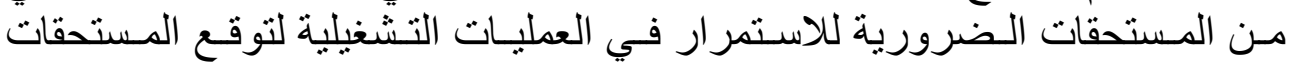

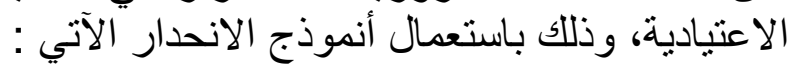

Expected Discretionary Accruals it $=$ Total Accruals it $/$ Asseti $_{\mathrm{t}-1}$ $\left[\mathrm{A}_{\mathrm{i} 1}\left(1 /\right.\right.$ Asseti $\left._{\mathrm{t}-1}\right)+\mathrm{B}_{\mathrm{i} 1}\left(\Delta\right.$ Revenue $_{\mathrm{it}} /$ Asseti $\left._{\mathrm{t}-1}\right)+\mathrm{B}_{\mathrm{i} 2}$ (Gross property plant and equipment / Asseti $\left.i_{t-1}\right)$ ]

$$
\text { إذ يعتمد الأنموذج على المتغير ات الآتية : }
$$

i تمثنل المستحقات المقدرة للمنظمـة Expected Discretionary Accruals it في سنة $t$.

o Total Accruals it

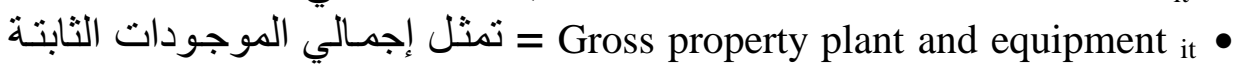

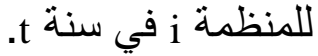

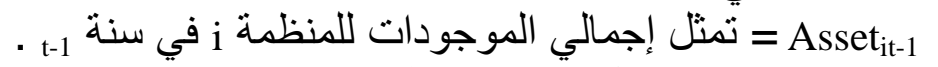

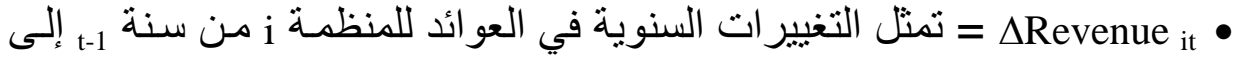

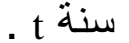

= تمثنل معـاملات متعلقة بهذا الأنموذج و على وفق مـا جـاء بـهـ

$$
\text { وقد حسبها بأنها تمثل الرقم } 1 \text {. Jones }
$$

Modified Jones Model : (Ibrahim, 2004, 15). \&

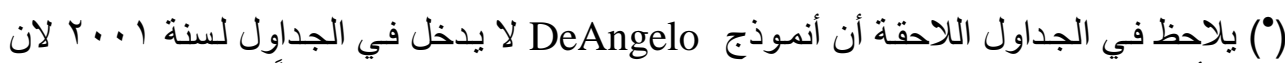

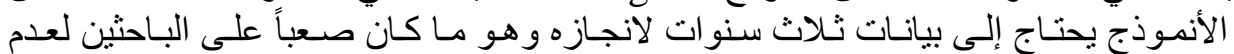

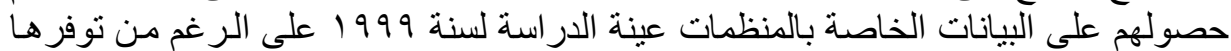




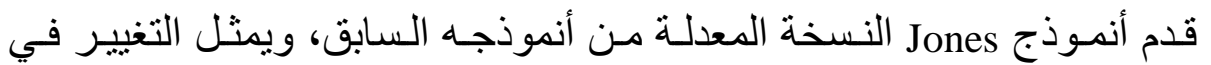

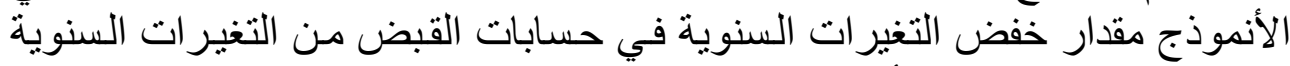

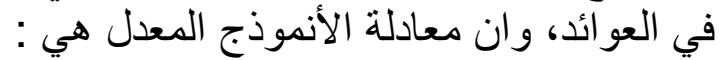

Expected Discretionary Accruals it $=$ Total Accruals it $/$ Asseti $_{\mathrm{t}-1}$ $\left[\mathrm{A}_{\mathrm{i} 1}\left(1 /\right.\right.$ Asseti $\left._{\mathrm{t}-1}\right)+\mathrm{B}_{\mathrm{i} 1}\left(\left(\Delta\right.\right.$ Revenue $_{\mathrm{it}}-\Delta$ Accounts Receivable $\left._{\mathrm{it}}\right) /$ Asseti $\left._{\mathrm{t}-1}\right)+$ $\mathrm{B}_{\mathrm{i} 2}$ (Gross property plant and equipment it / Asseti $\left.\mathrm{i}_{\mathrm{t}-1}\right)$ ]

$$
\text { وتتكون متغير ات الأنموذج المعدل مما يأتي : }
$$

i تمثنل المستحقات المقدرة للمنظمـة Expected Discretionary Accruals it في سنة

Total Accruals it Gross property plant and equipment it

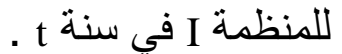

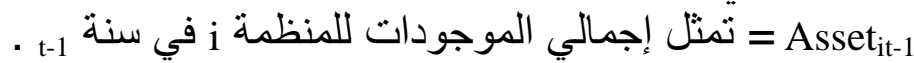
$\Delta$ Revenue ${ }_{\text {it }}$

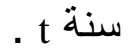

AAccounts Receivable it

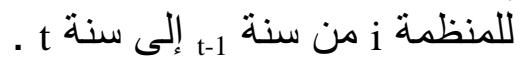

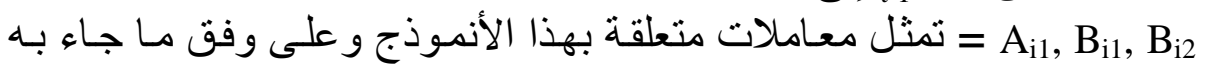
Jones وتتكون المستحقات الكلية للنماذج السابقة مها ئأتي:

Total accruals ${ }_{i t}=$ Current assets ${ }_{\text {it }}-$ Cash and cash equivalents ${ }_{i t}-$ Current liabilities it $+\Delta$ in debt included in current liabilities it - depreciation and amortization $_{\text {it }}$

إذ إن

e Total accruals it i تمثل التغيرات السنوية في الموجودات المتداولة للمنظة Current assets it •

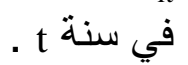
Cash and cash equivalents ${ }_{\text {it }}$ • تمثل التغير ات السنوية في النقد، ومـا يعادله ل المنظمة i في سنة •

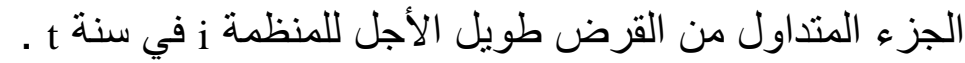

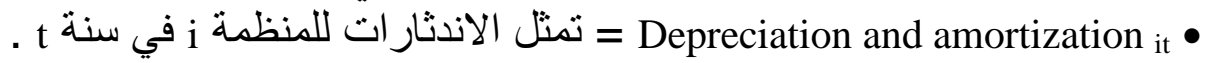

ويعد من أهم الأدوات المعتمدة في الدراسة، الذئي الذي يعتمد تحليل العلاقة بين عدد ب. الانحدار المتعدد الخطي من المتغير ات المعتمدة، و المتغير الادوات المستقلة. 


\section{مفهوم إدارة العوائد وتطورها}

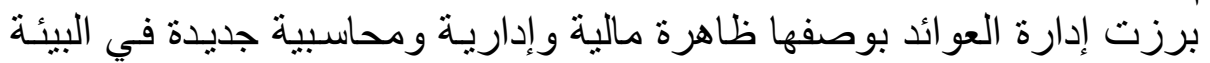

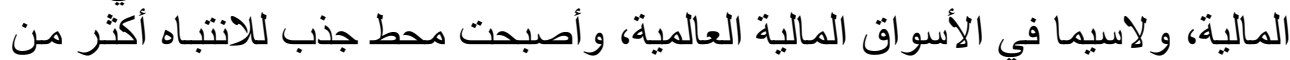

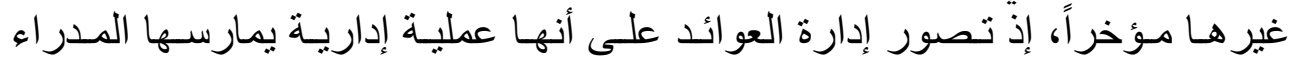

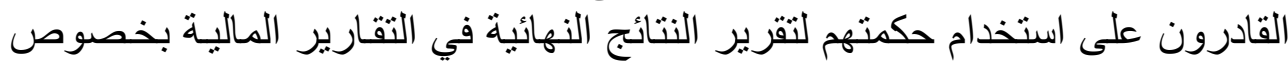
الأداء الاقتصادي للمنظمة، أو للتأثير في نتائج التعاقدية.

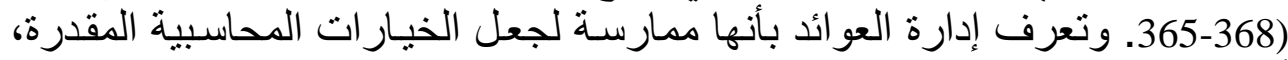

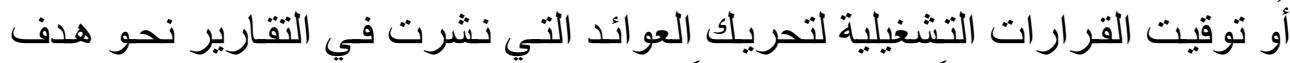

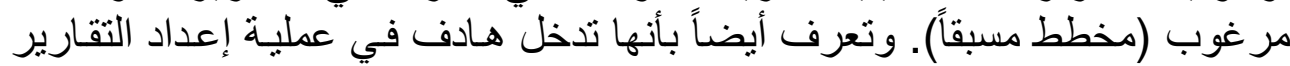

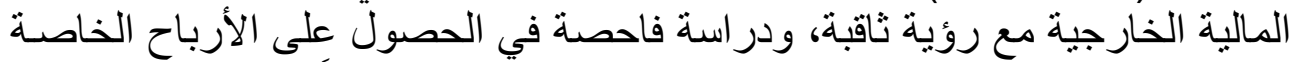

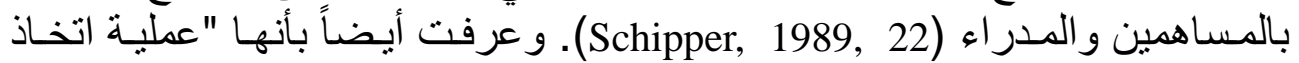

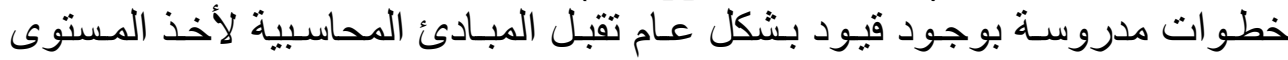
المطلوب من الأرباح التي نشرت في التقارير المالية" (Sidney \& other, 1986, 24).

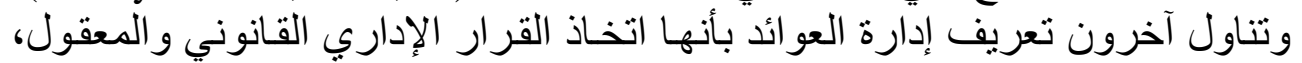

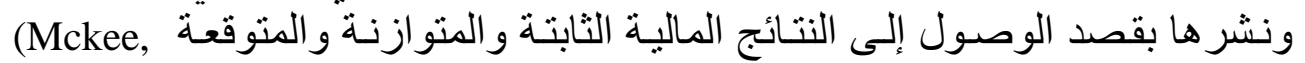
. 2005, 1)

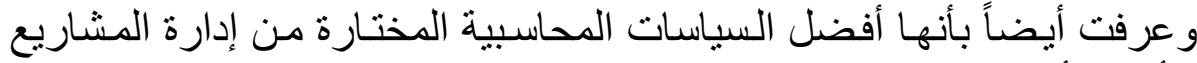

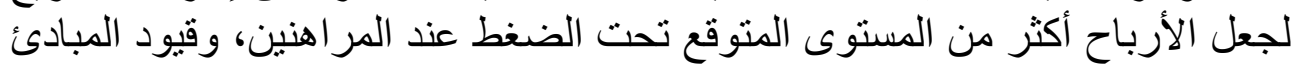

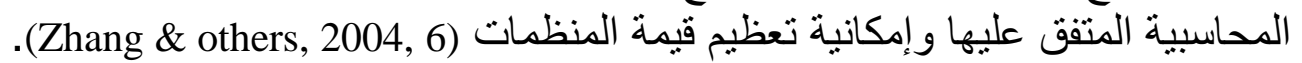

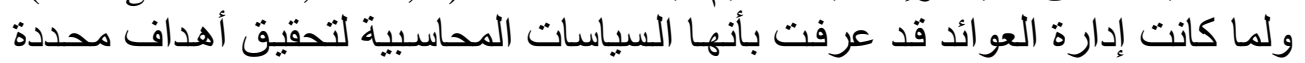

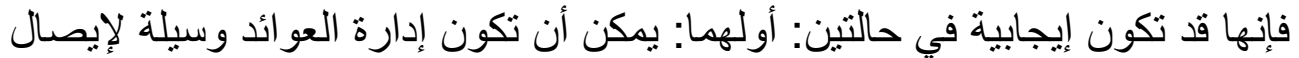

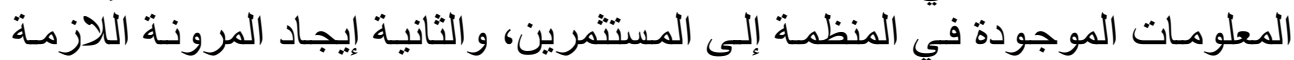

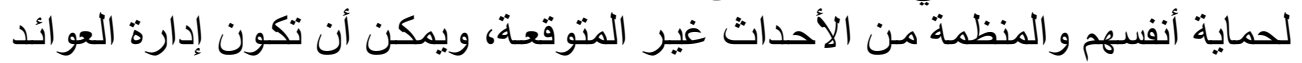

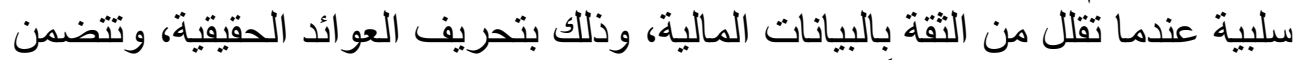

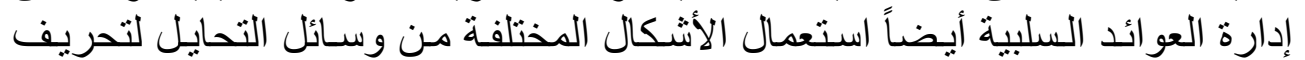

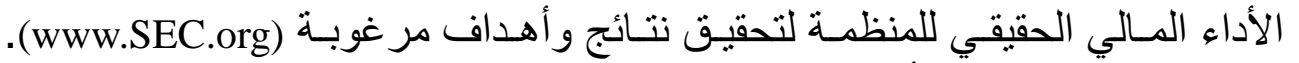

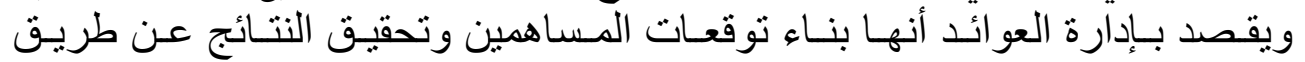
الطر ائق الثر عية (القانونية)، و غير الثرعية (غير القانونية) (www.fei.org).

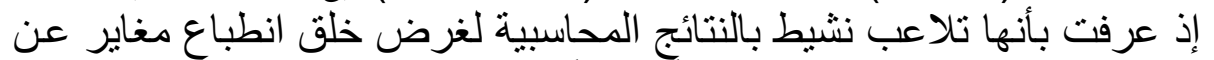

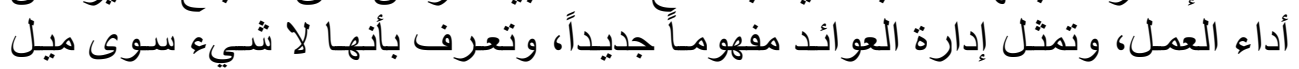

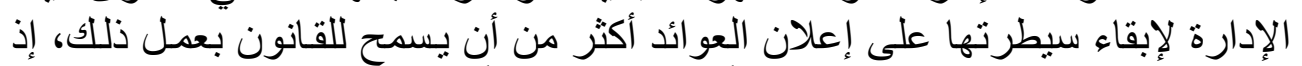

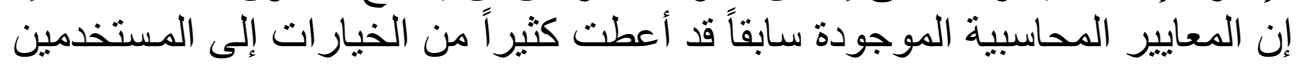

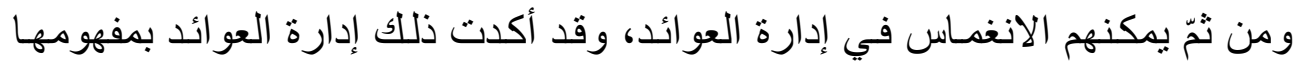

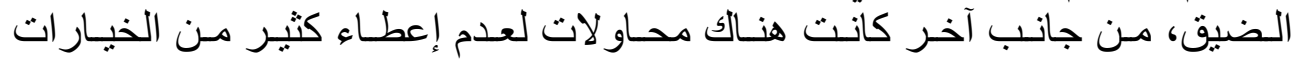

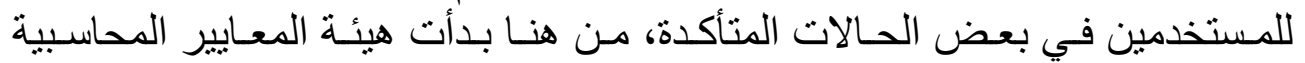

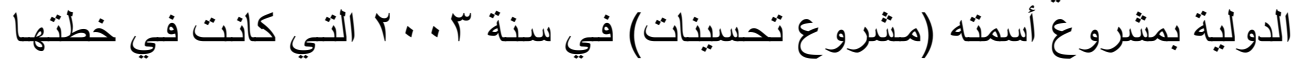


إغـلاق عـدد مـن هـذه الخيـار ات المتـوافرة لـدى مسستخدمي المعـايير المحاسـبية

. (Comisky \& Mulford, 1996, 360)

ويرى Millstein بأن إدارة العو ائد تمثل إستر اتيجية إدارية لاى بعض المدر اء

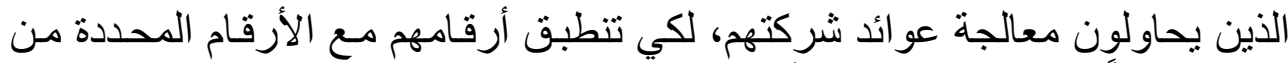

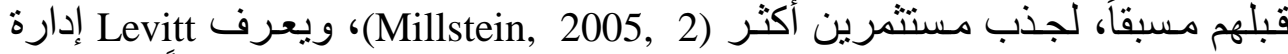
العو ائد بأنها ممارسات تعكس بو اسطتها تقارير العو ائد رغبات الإدارة بدلاًا من الأداء

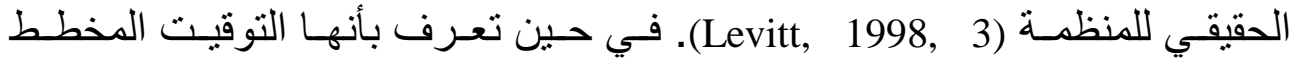

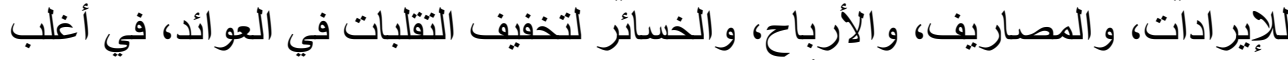

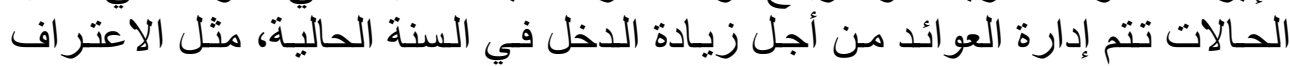
بالمبيعات قبل أن تكتمل من اجل زيادة العوائد، ويمكن أن تستعمل لتخفيض العن العوائد

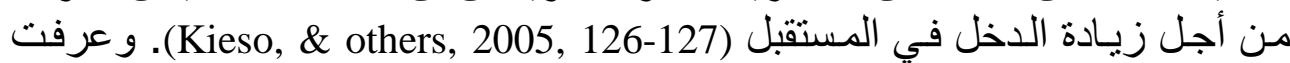

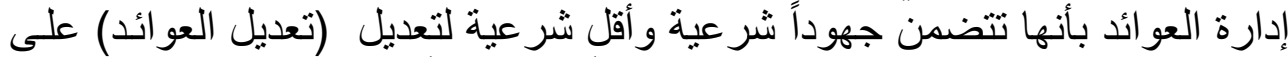

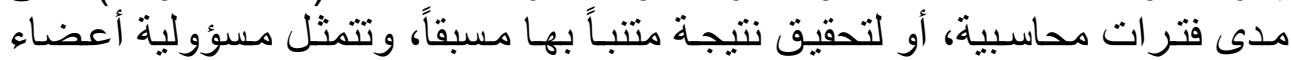

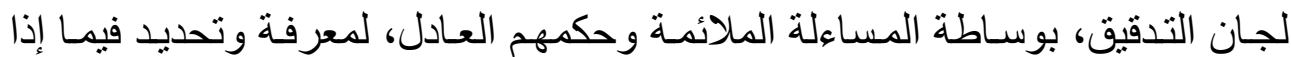

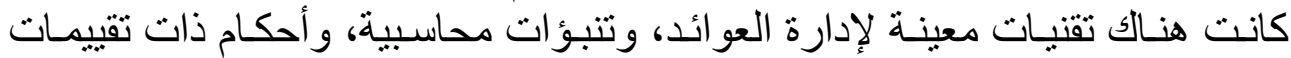

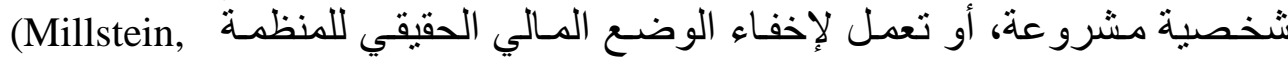
$.2005,1)$

لقد بينت الدراسات أن إدارة العوائد قد تتجم عن رغبة المدير لإشر الك الآخرين

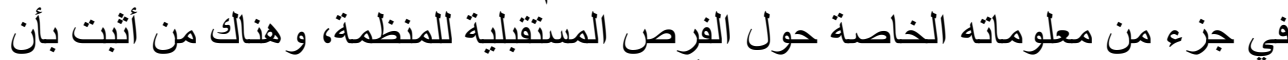

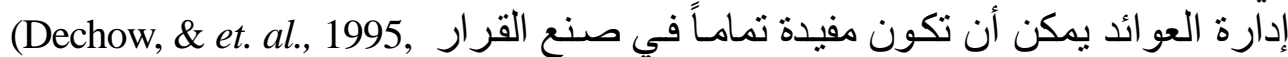

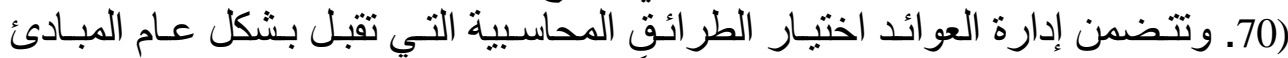

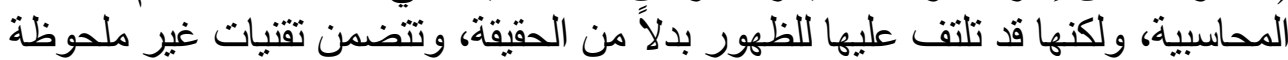
(Stephen \& et. al. , أيضاً مثل تغيير العوائد المنشورة عن طريق (توقيت الأداء) .2000, 3)

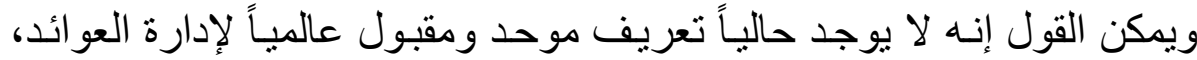

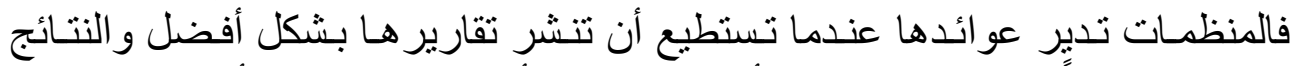

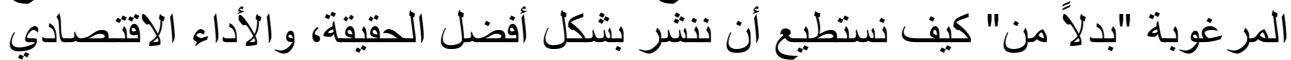

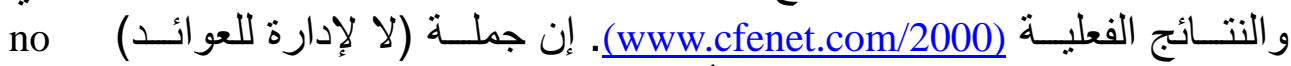
earnings management عدم الاستفادة من علاقة ونوقيت التقارير المالية بوصفها مقاييس للنشاط الاقتصادي

.(Bruner\& et. al., 2004, 500)

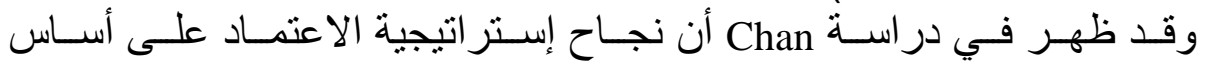

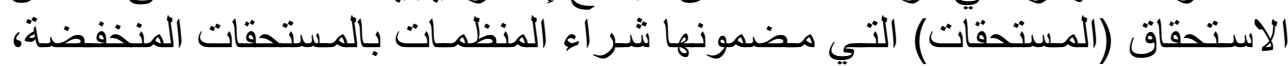

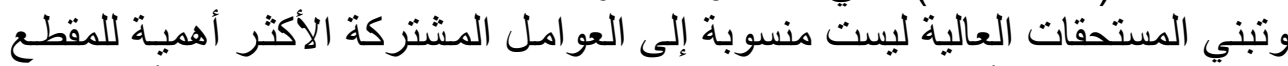

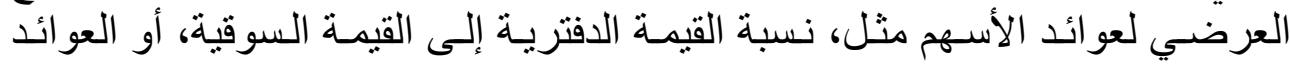

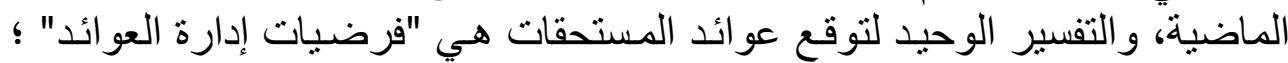

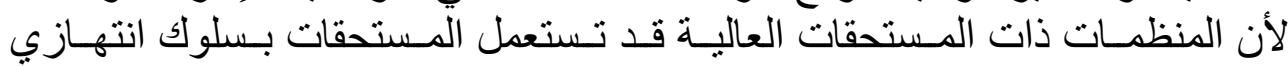


لتضخيم العوائد المنشورة في التقارير ، وبشكل عام يميل المستثمرون إلى التثبيت

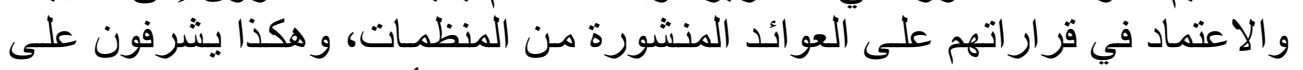

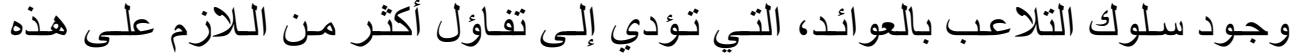

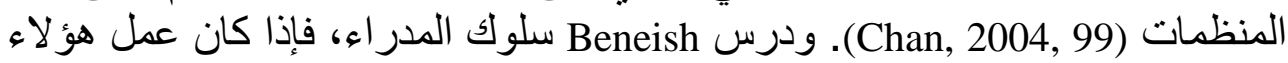

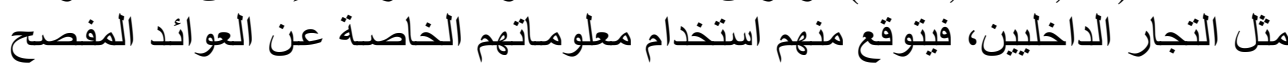

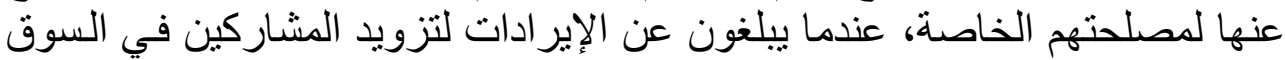

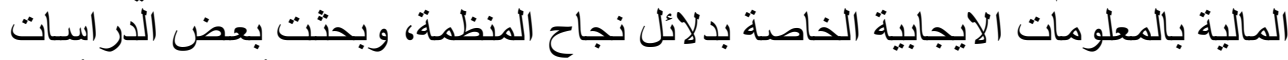

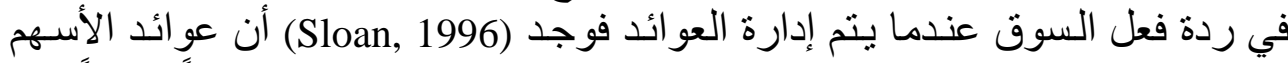

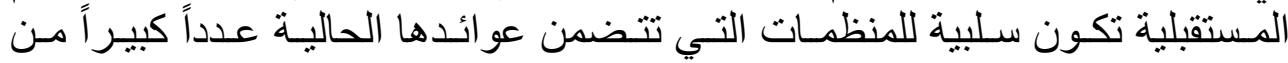
(Beneish, المستحقات، وايجابية للمنظمات ذات المكونات التي تكون مستحقات قليلة

إذ تقدم الدر اسات الحاليـة تقبيمـاً مباشـراً عن تـأثثر المستحقات الحاليـة في أداء

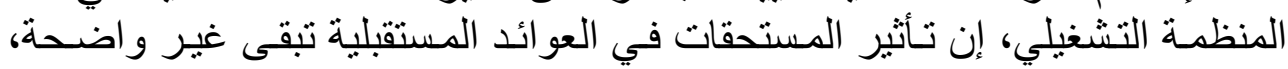
وتحتاج للمزيد من الدراسة (Chan, 1999, 112) .

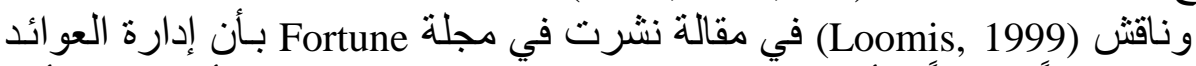

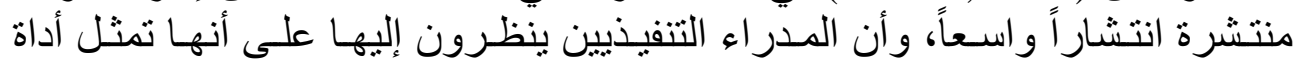

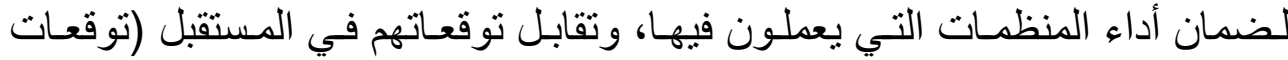

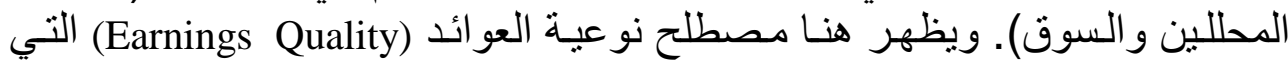

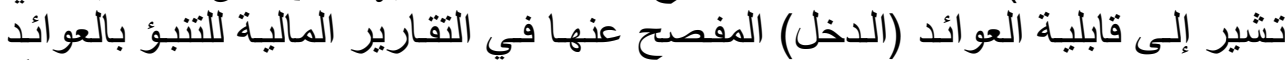

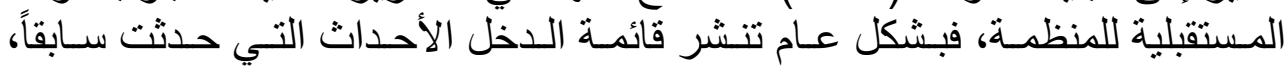
ولتعزيز القيمة المتنبأ بها بالبيانات المالية، يفصل المحللون بين مؤشر ات اتلئ (العوائد

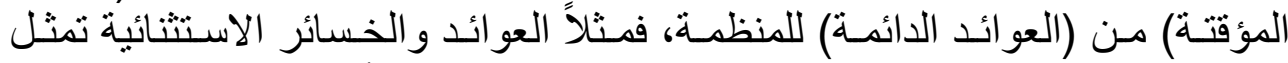

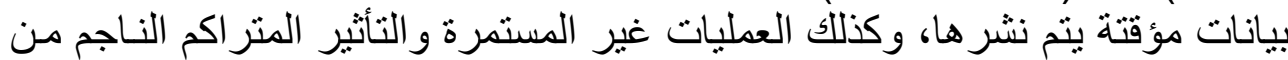

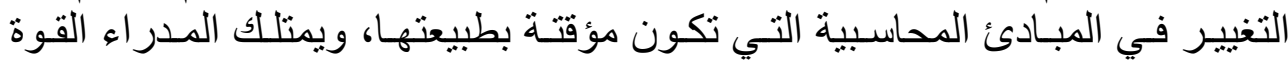

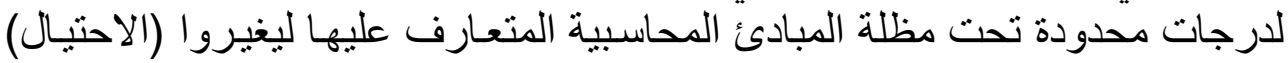

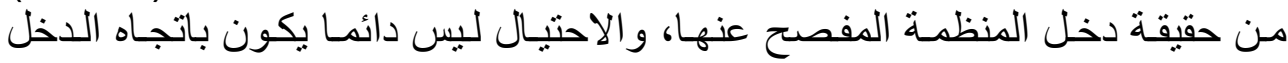
العالي (Spiceland \& et. al., 2000, 131-132) .

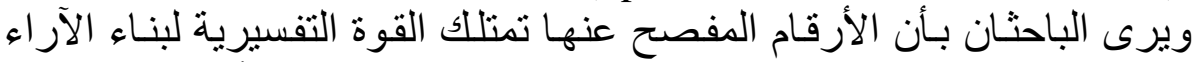

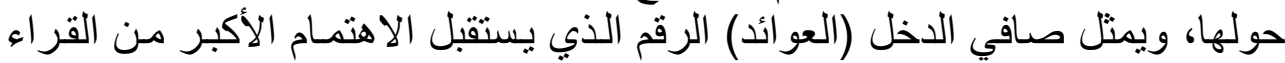

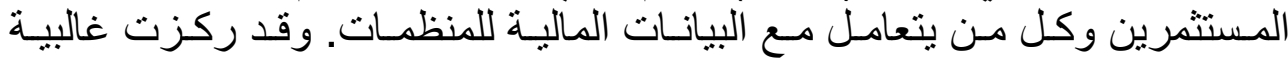

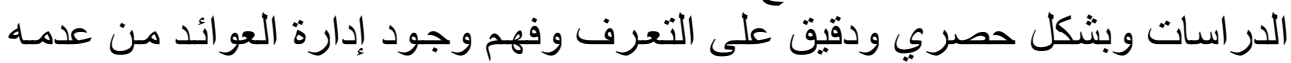

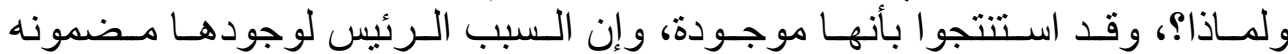

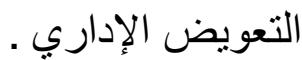

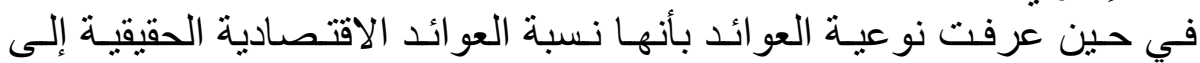

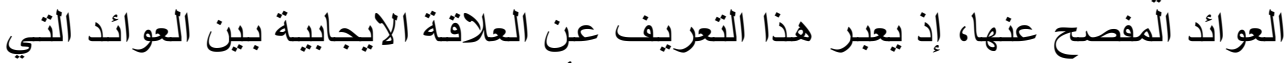

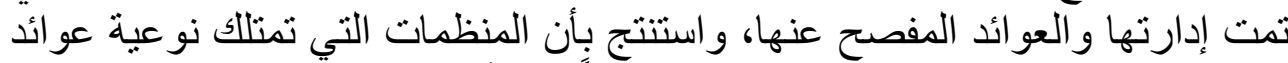

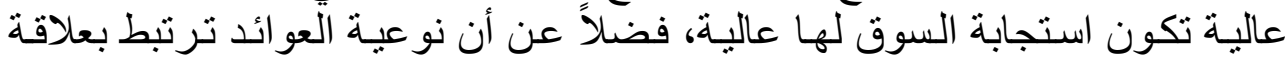




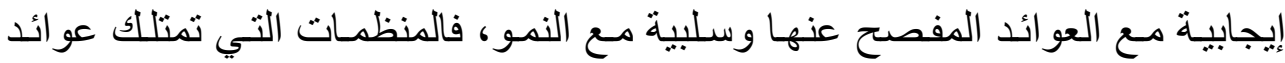

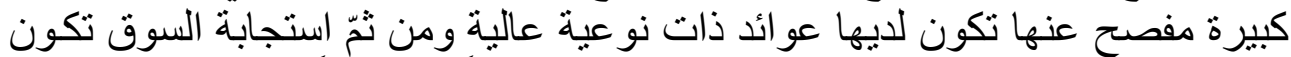

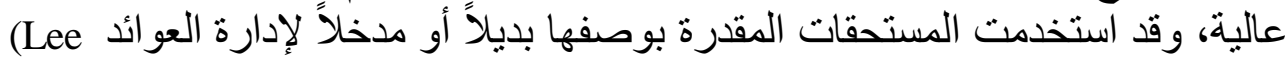

.\& Others, 2005, 34)

وحساول Whelan \& McNamara معرفـة تـأثثر العوائـد في القيمـة المتعلقـة

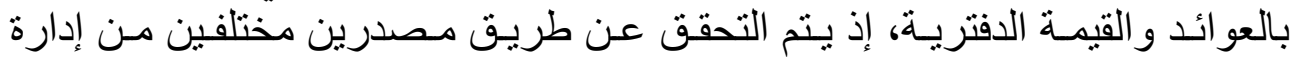

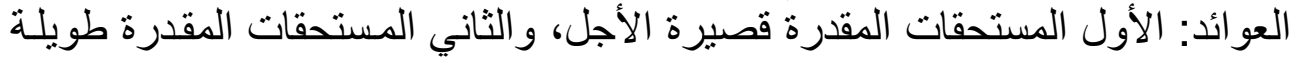

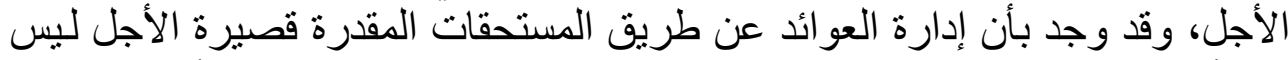

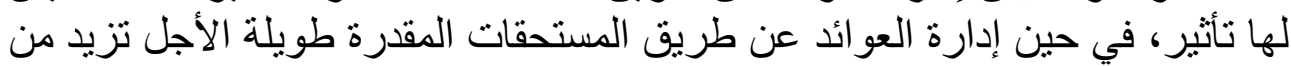

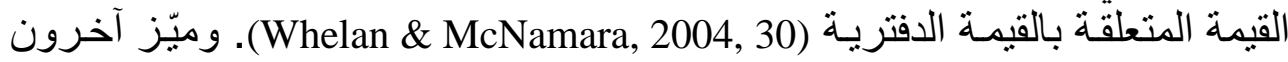

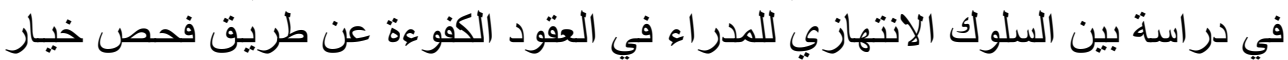

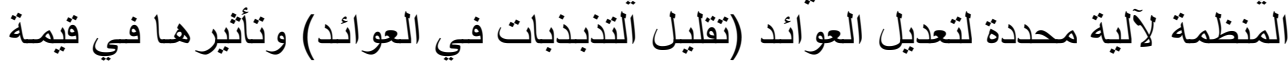

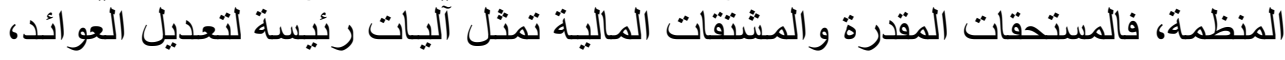

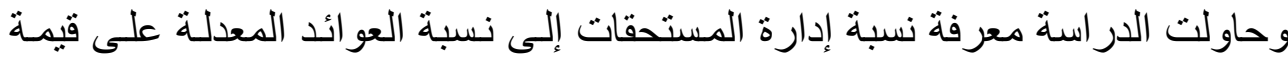

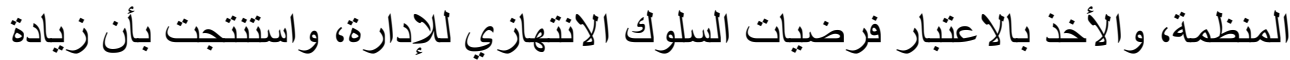

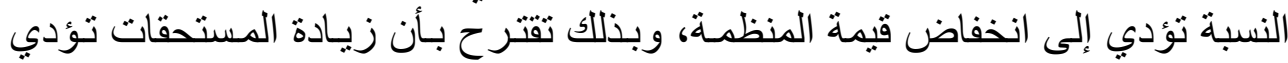

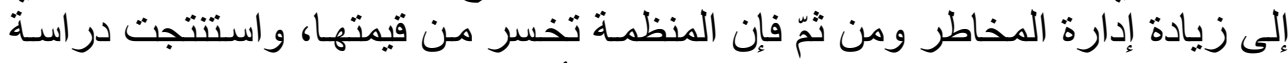
(Barton, 2001; Pincus \& Rajgopal, 2002)

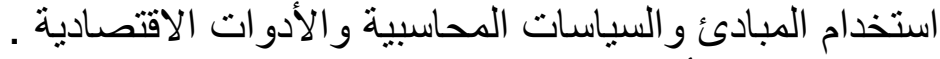

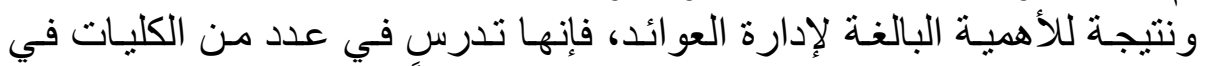

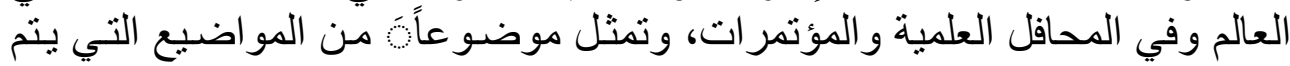

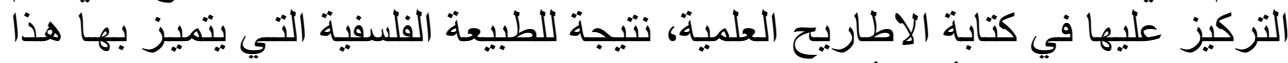

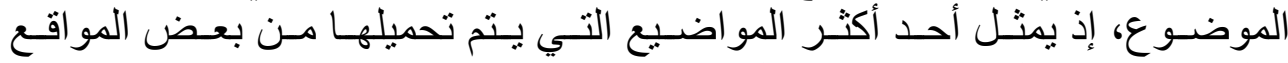

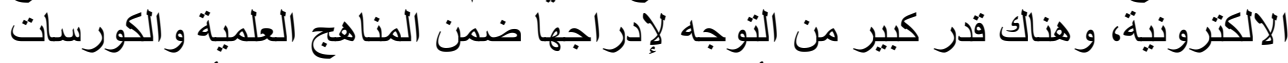

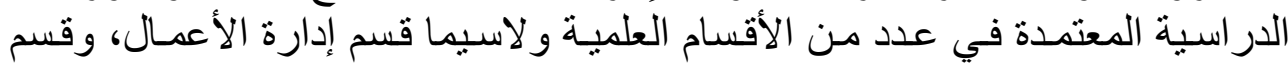
المالية و المصسارف و التّمويل، وقسم المحاسبة (Zhang \& Others, 2004, 7-26).

دور إدارة العوائد في تعظيم قيمة المنظمة حاولت دراسات أخرى معرفة كيفية تأثثر المستحقات الكلية الحالية في العوائد،

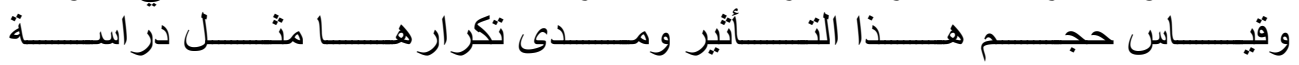
(Konan Chan, Narasimhan Jegadeesh, Theodore Sougiannis 2004) أن الأسهم ذات المستحقات العاليـة تفشل بشكل ثابـ أكثر من فن

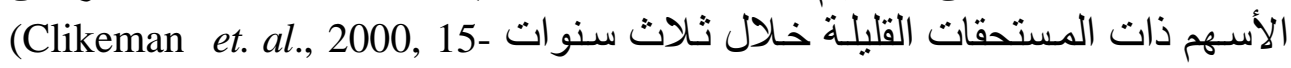

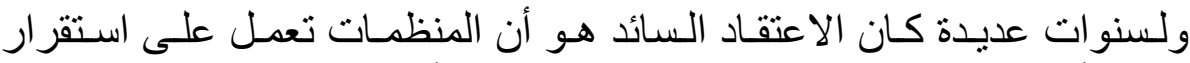

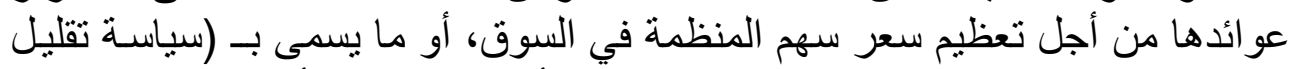
التذبذبات) في الدخل ومحاولة استقرار ها في الأجل الطويل، لأن تغيير ات ات العو ائد 


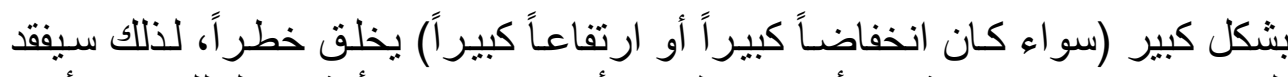

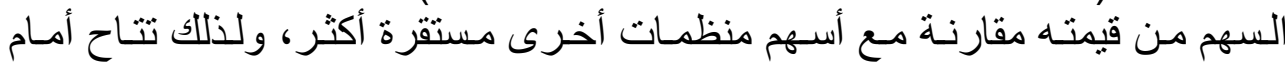

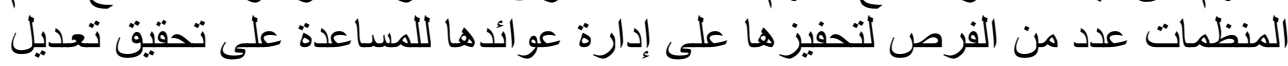

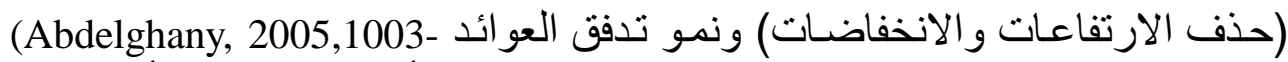

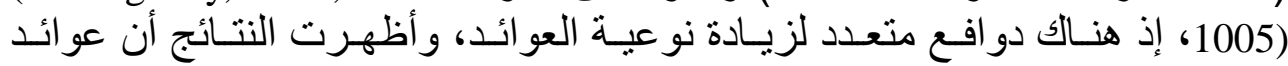

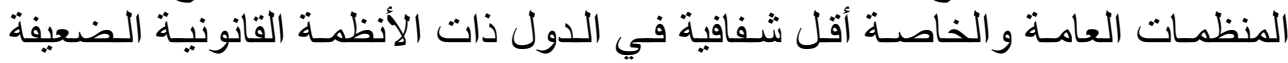

.(Burgstahler et. al., 2001, 35) وتمت در اسة تقدير إدارة العوائد وتكر ار ها عن طريق نمـاذج محددة، وأستنتج

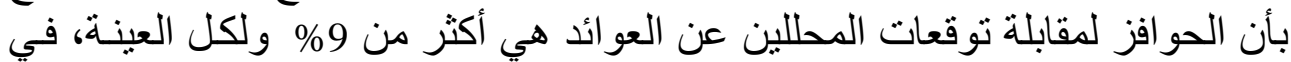

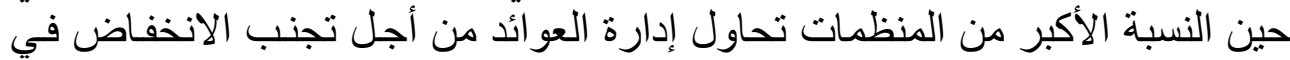

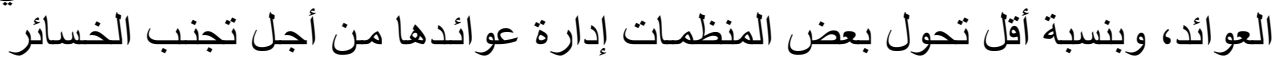
.(Chen et. al., 2005, 26)

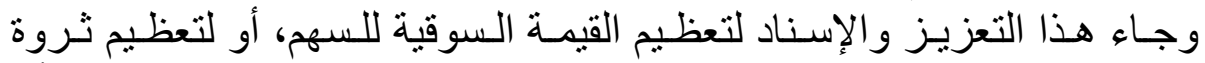

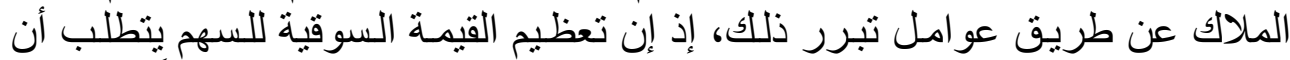

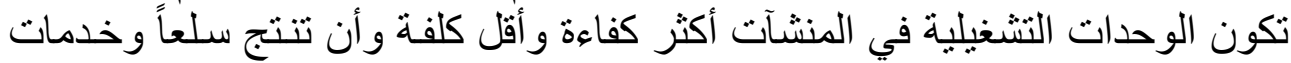

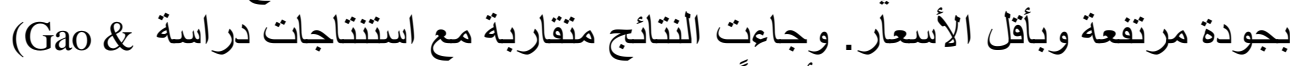

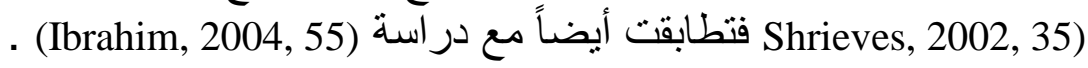

\section{ثناتياً- معالجة البيانات وتطبيق النماذج}

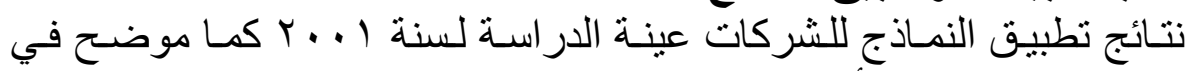

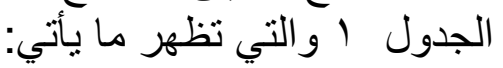

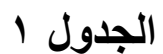

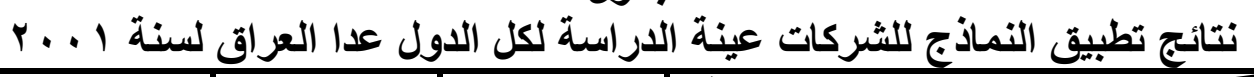

\begin{tabular}{|c|c|c|c|}
\hline Modified Jones & Jones & Healy & النماذٔ| \\
\hline 0.246 & 0.085 & 0.124 & Mean \\
\hline 1.304 & 1.233 & 1.220 & Standard Deviation \\
\hline-1.243 & -1.626 & -1.489 & Minimum \\
\hline 7.890 & 7.946 & 7.963 & Maximum \\
\hline 25.377 & 35.136 & 36.217 & Kurtosis \\
\hline 4.640 & 5.501 & 5.627 & Skewness \\
\hline
\end{tabular}

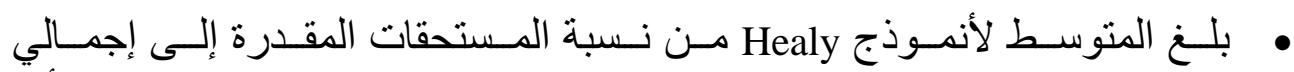

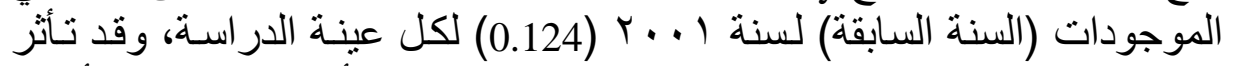

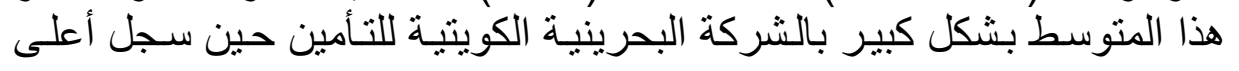


نسبة منها بلغت (7.963)، في حين سجل المصرف الأهلي للاستثمار أقل نسبة

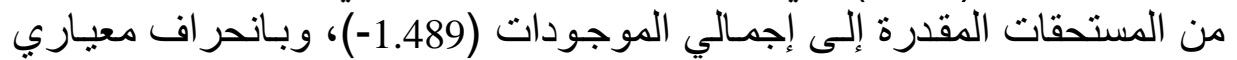

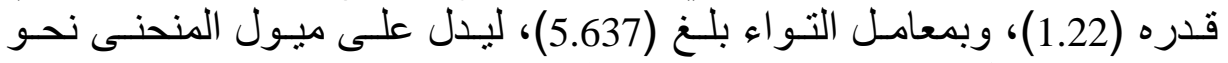

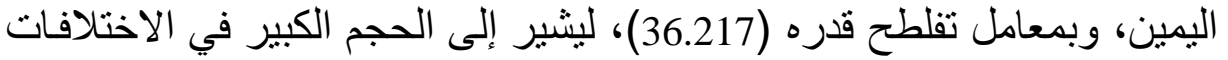
بين شركات عينة الدر اسة في سنة 2001 .

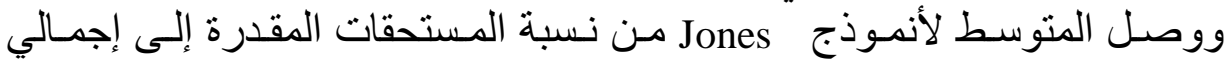

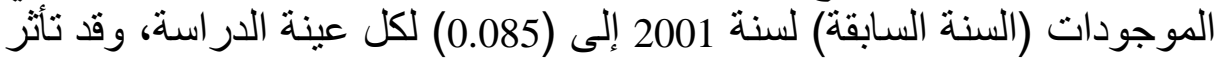

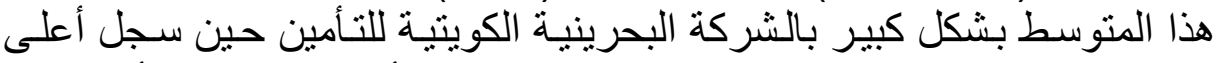

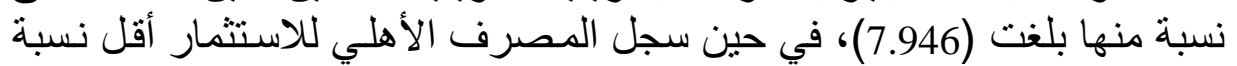

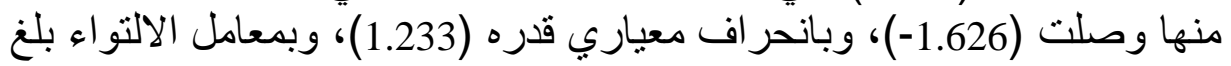

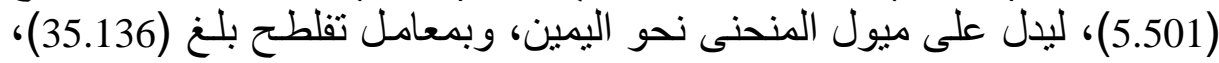

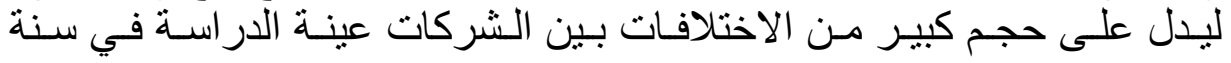
r... ويلحظ بأن المتوسط لأنموذج M.Jones من نسبة المستحقات المقدرة إلى إجمالي

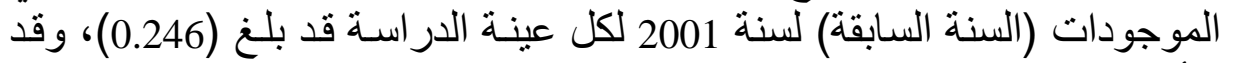

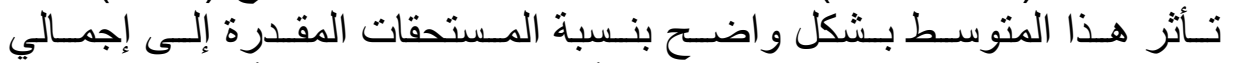

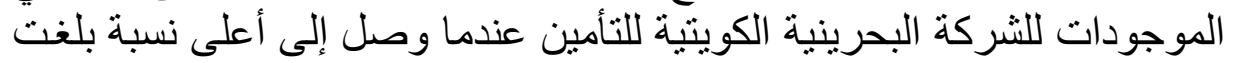

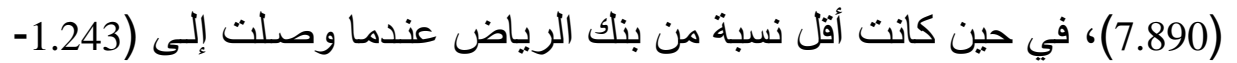

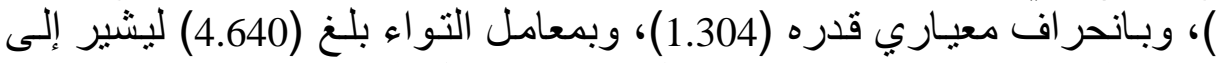

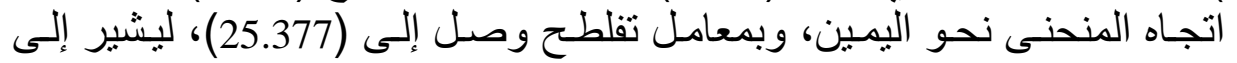

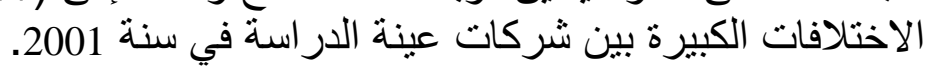

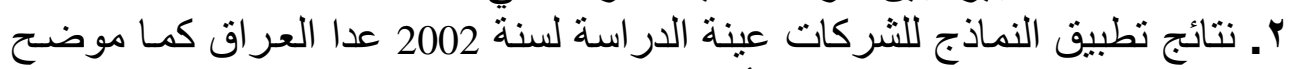
في الجدول r و التي تظهر ما يأتي:

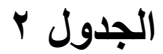

نتائج تطبيق النماذج للشركات عينة الاراسة لكل الدول لسنة r ب . . ب عدا العراق

\begin{tabular}{|c|c|c|c|r|}
\hline $\begin{array}{c}\text { Modified } \\
\text { Jones }\end{array}$ & Jones & DeAngelo & Healy & \multicolumn{1}{|c|}{ المقاييس الإحصائية } \\
\hline-0.351 & -0.266 & -0.790 & -0.249 & Mean \\
\hline 1.705 & 1.367 & 3.494 & 1.365 & Standard Deviation \\
\hline-8.946 & -8.830 & -17.323 & -8.803 & Minimum \\
\hline 1.235 & 0.878 & 1.787 & 0.891 & Maximum \\
\hline 19.480 & 39.152 & 18.454 & 39.125 & Kurtosis \\
\hline-4.389 & -6.133 & -4.366 & -6.133 & Skewness \\
\hline
\end{tabular}

تبـين بـأن المتوسط لأنمـوذج Healy مـن نسبة المستحقات المقدرة إلى إجمـالي

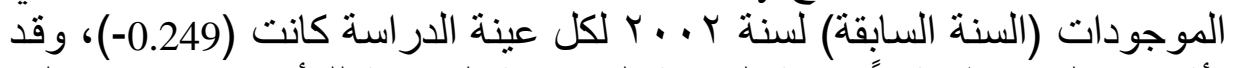

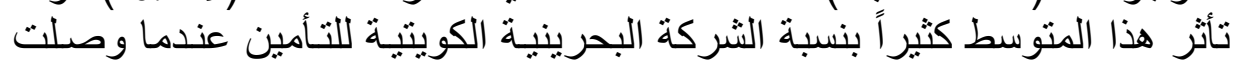




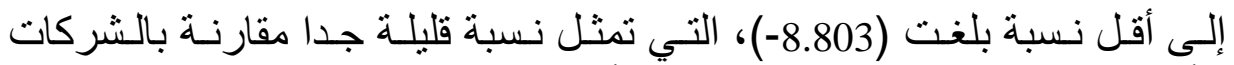

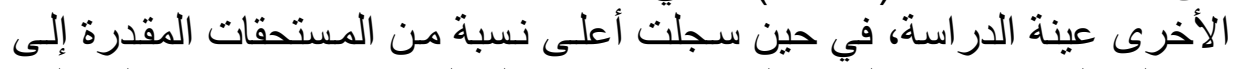

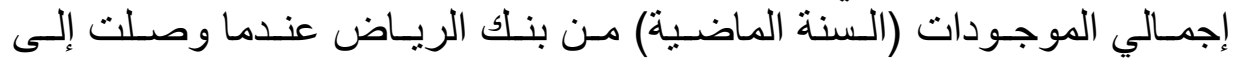

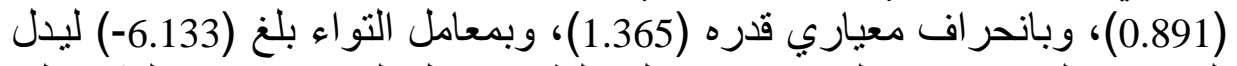

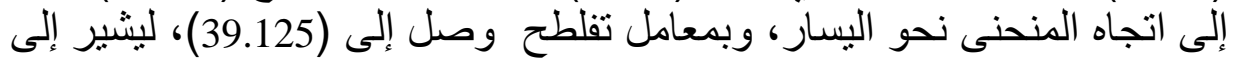

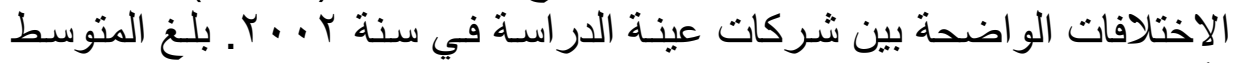

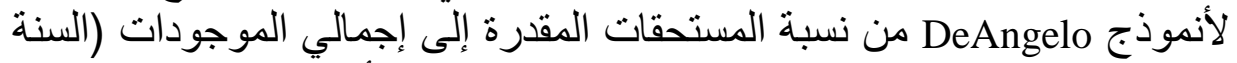

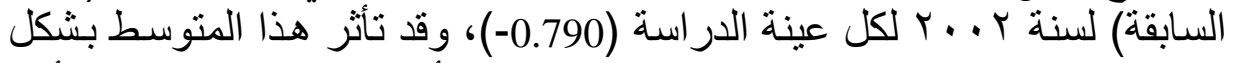

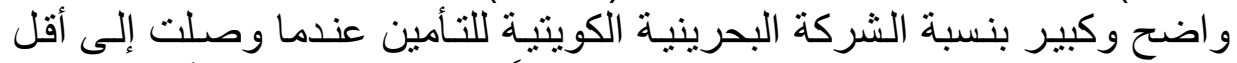

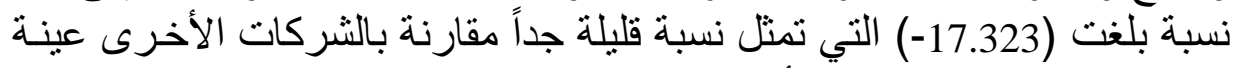

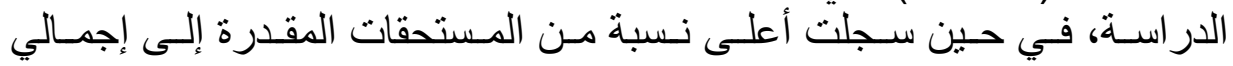

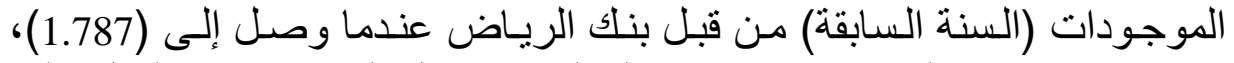

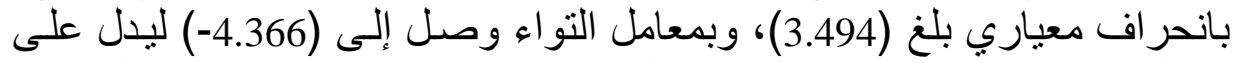

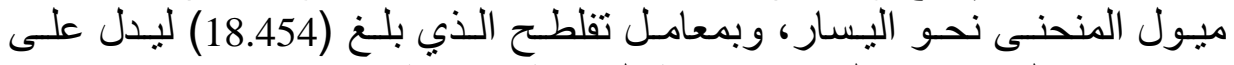

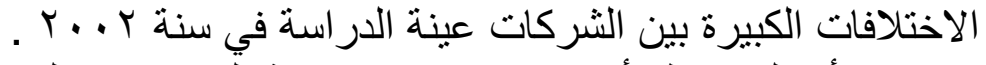

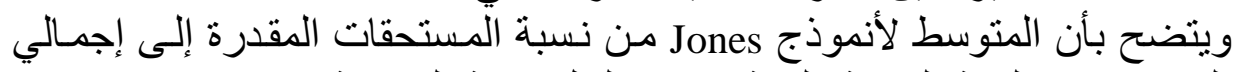

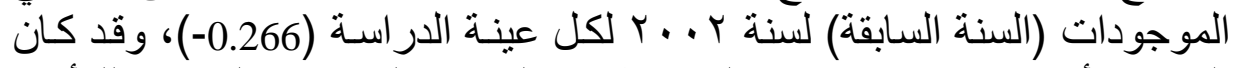
المؤثر الأقوى في انخفاض هذا المتوسط هي الشركة البحرينيـة الكويتيـة للتـأمين

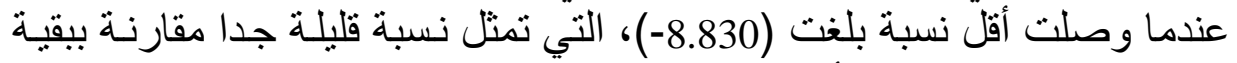

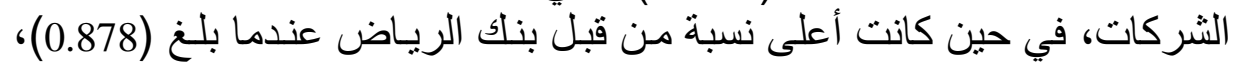

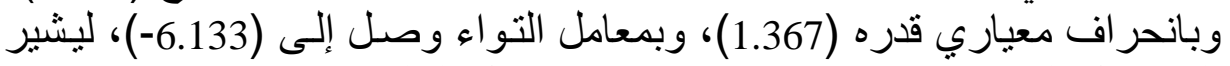

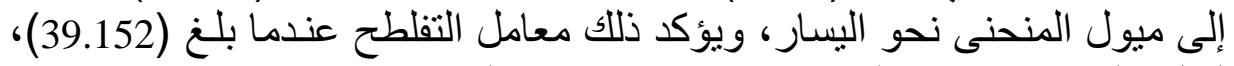

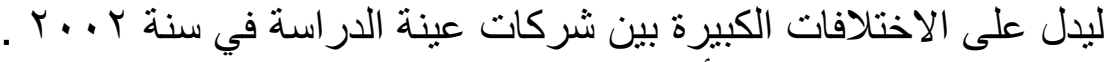

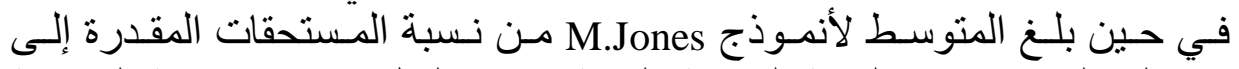

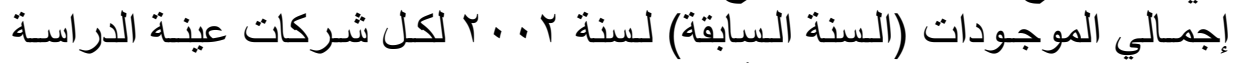

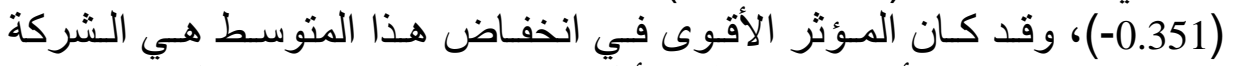

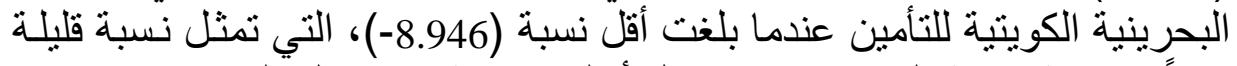

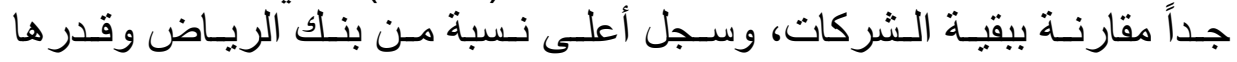

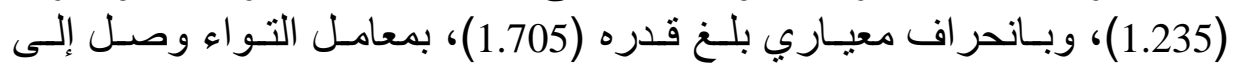

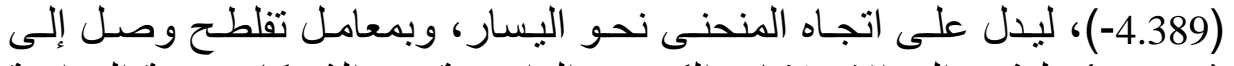

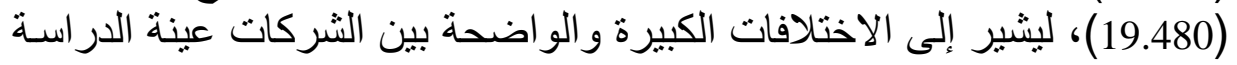

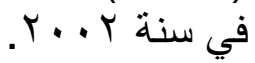

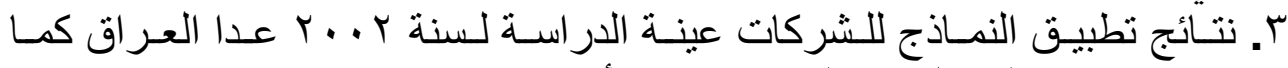

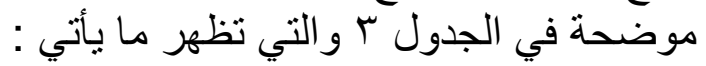

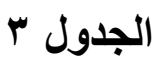

نتائج تطبيق النماذج للشركات عينة الدراسة لسنة 2003 عدا العراق 
الجميل والدوسكي [ • ؛] إدارة العو ائد كمدخل لتعظيم قيمة المنظمة .

\begin{tabular}{|c|c|c|c|r|}
\hline $\begin{array}{c}\text { Modified } \\
\text { Jones }\end{array}$ & Jones & DeAngelo & Healy & المقاييس الإحصائيه \\
\hline 0.044 & -0.078 & 3.180 & -0.027 & Mean \\
\hline 6.900 & 4.630 & 1.310 & 7.630 & Standard Deviation \\
\hline-3.844 & -3.728 & -3.637 & -3.612 & Minimum \\
\hline 1.357 & 1.046 & 7.393 & 1.318 & Maximum \\
\hline 24.814 & 27.517 & 23.933 & 25.115 & Kurtosis \\
\hline-4.201 & -4.526 & 3.549 & -4.118 & Skewness \\
\hline
\end{tabular}

$$
\text { يبين الجدول ب ما يأتي : بين }
$$

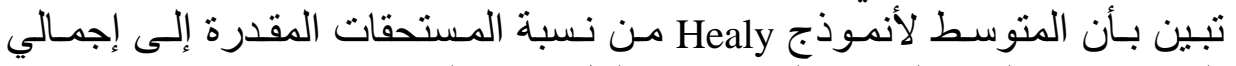

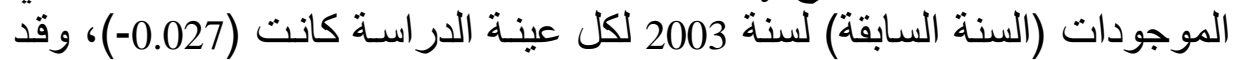

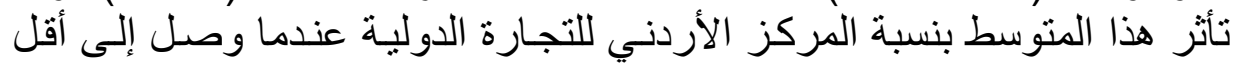

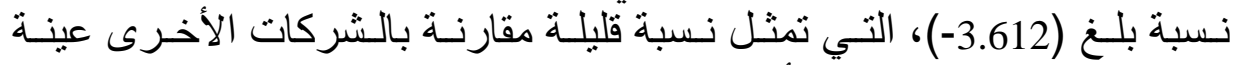

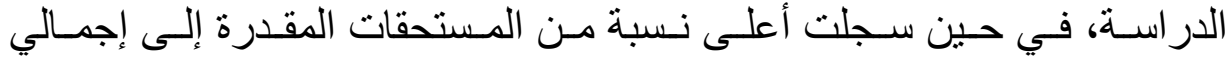

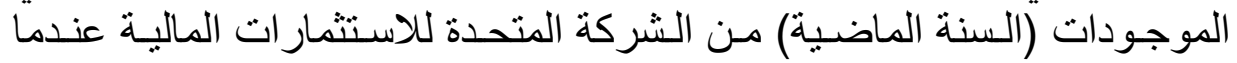

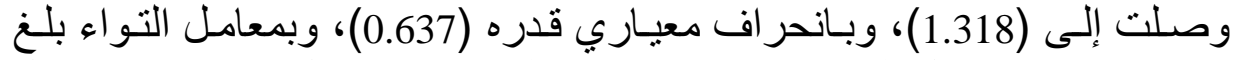

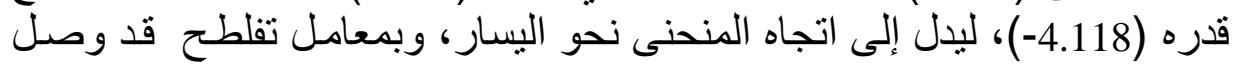

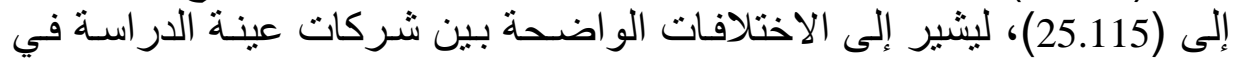
سنة r. . r.

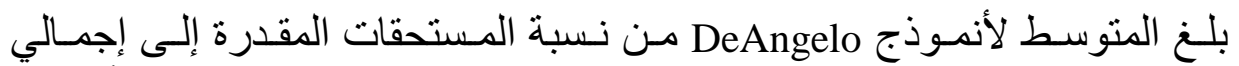

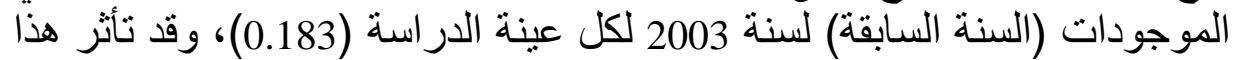

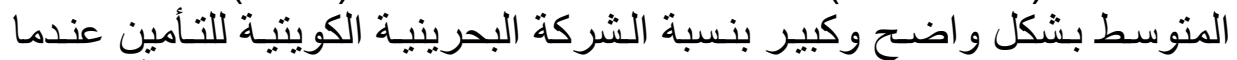

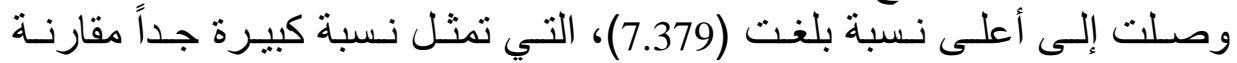

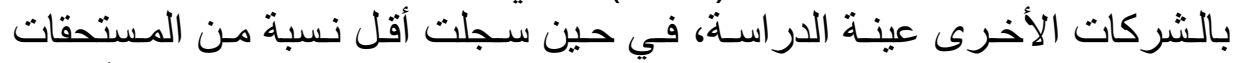

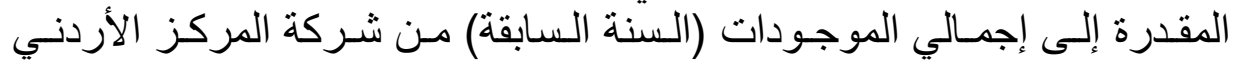

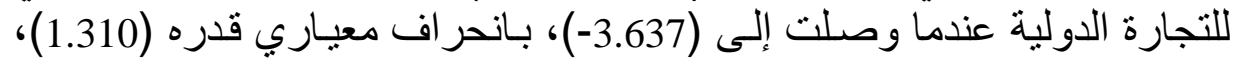

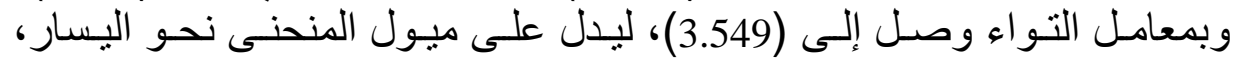
وبمعامل التفلطح بلغ قدره (23.933)، ليدل على الاختلافات الكبيرة بين الثركات

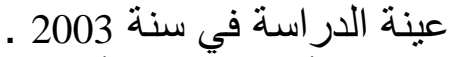

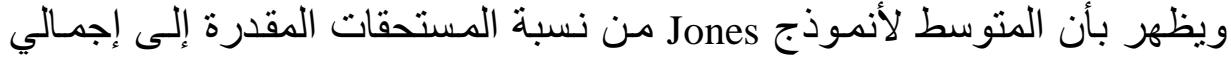

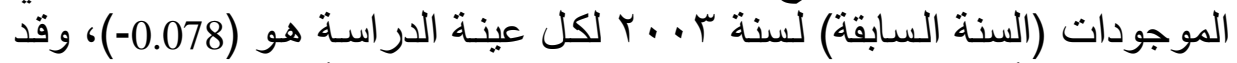
كان المؤثر الأقوى في انخفاض هذا المتوسط هو المركز الأردني للتجارة الدونة الدولية

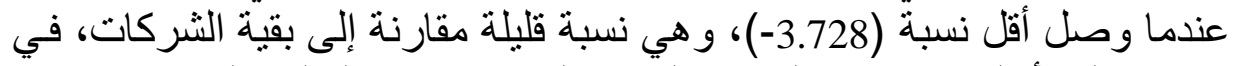

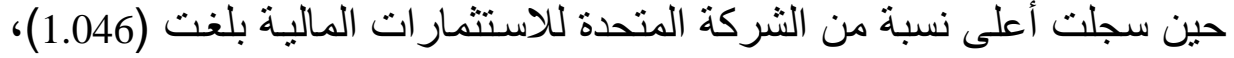

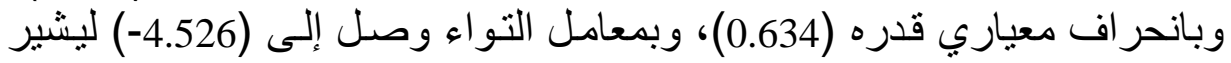

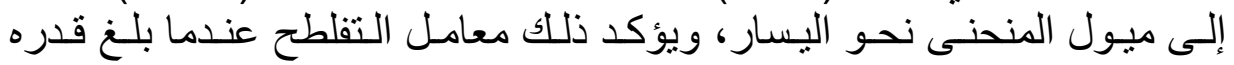


(27.517)، ليدل على الاختلافـات الكبيرة بين شركات عينـة الدر اسـة في سـنة 2003

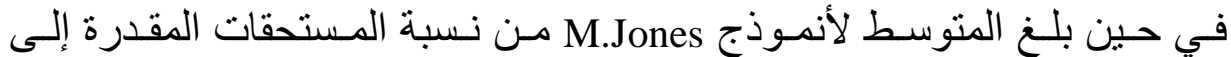

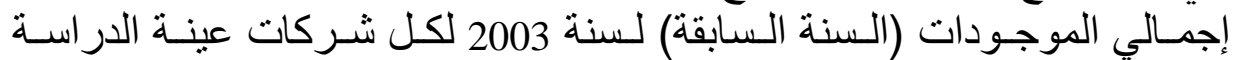
(0.044)، وقد كان المؤثر الأقوى في انخفاض هذا المتوسط هو المركز الأردني

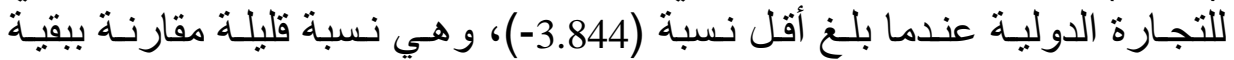

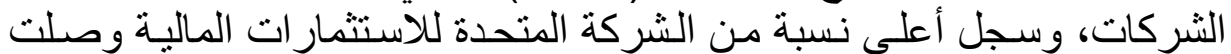

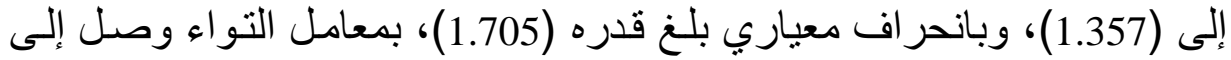

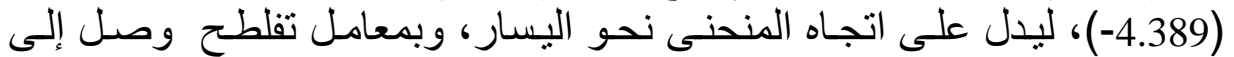

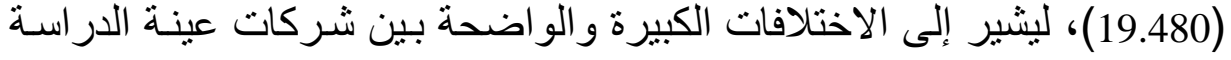

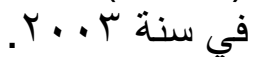

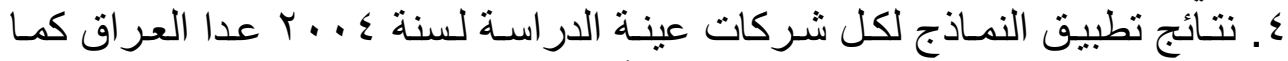

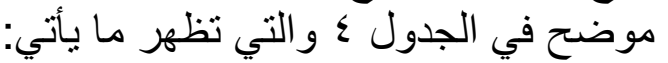

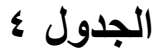

نتائج تطبيق النماذج للشركات عينة الاراسة لسنة 2004 عدا العراق

\begin{tabular}{|c|c|c|c|r|}
\hline $\begin{array}{c}\text { Modified } \\
\text { Jones }\end{array}$ & Jones & DeAngelo & Healy & Mean \\
\hline 0.064 & -0.024 & -0.633 & 0.199 & Standard Deviation \\
\hline 0.330 & 0.235 & 8.650 & 8.230 & Minimum \\
\hline-1.605 & -0.913 & -2.400 & -0.910 & Maximum \\
\hline 3.588 & 0.831 & 0.829 & 0.842 & Kurtosis \\
\hline 20.714 & 7.953 & 38.945 & 7.598 & Skewness \\
\hline 3.454 & -0.600 & -6.111 & -0.268 & \\
\hline
\end{tabular}

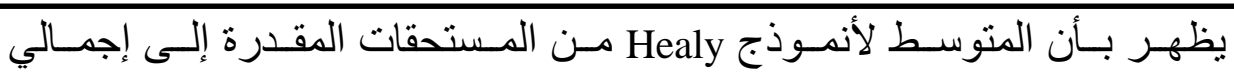

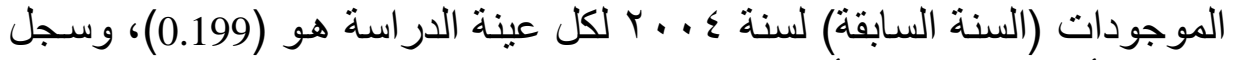

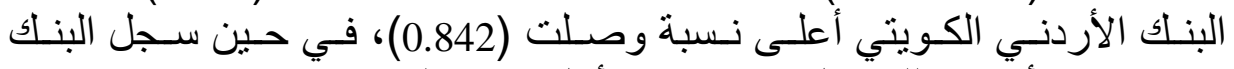

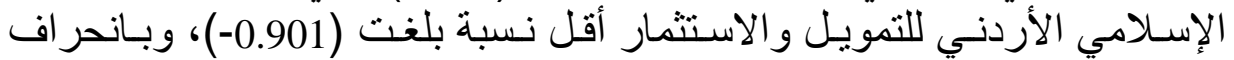




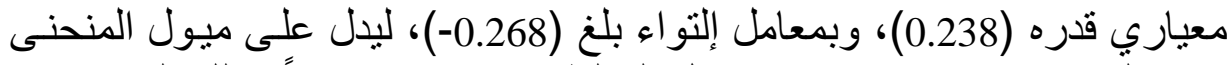

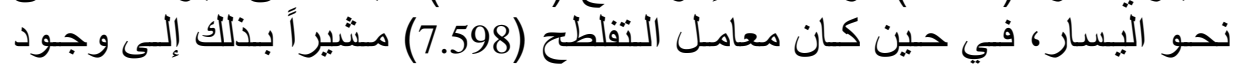

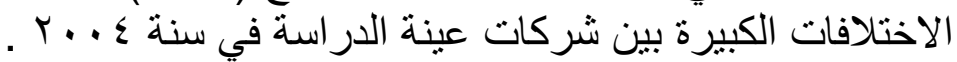

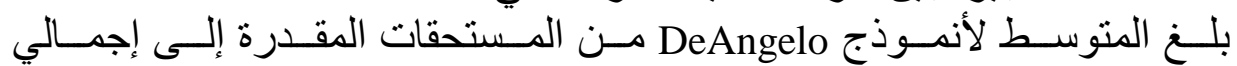

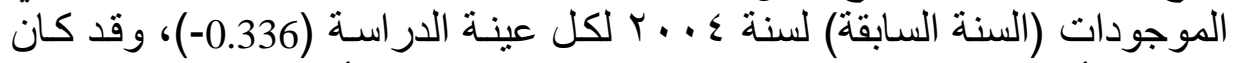

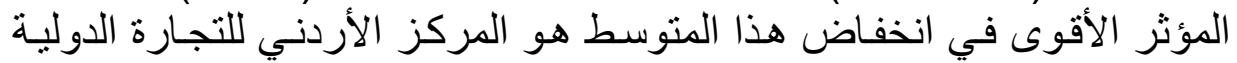

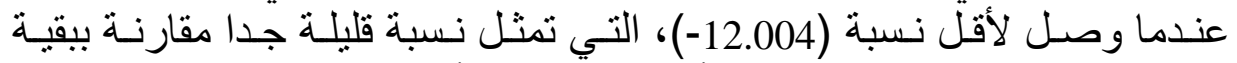

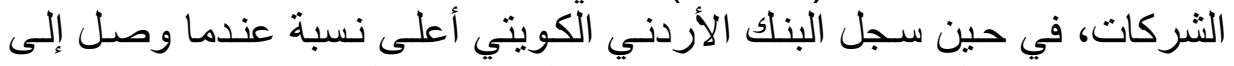

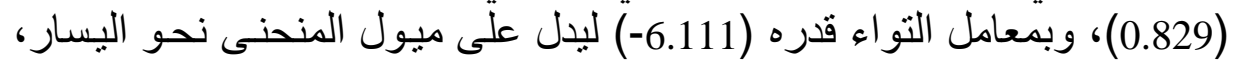

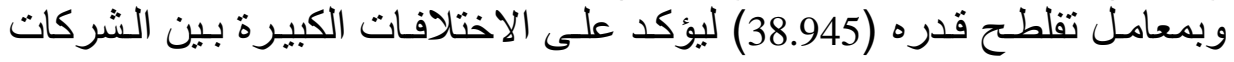

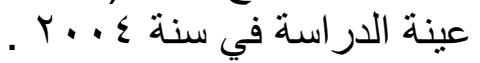

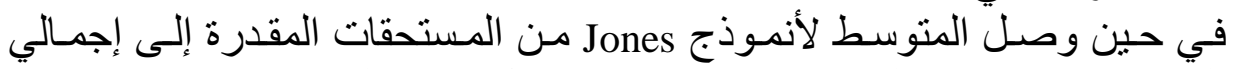

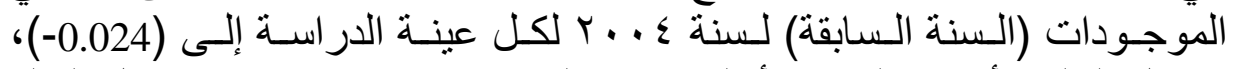

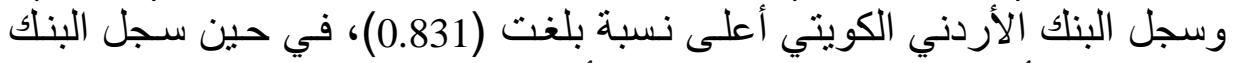

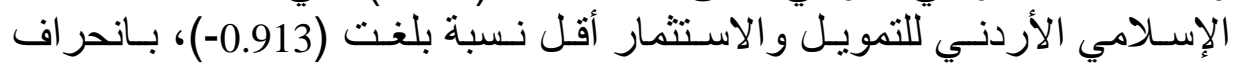

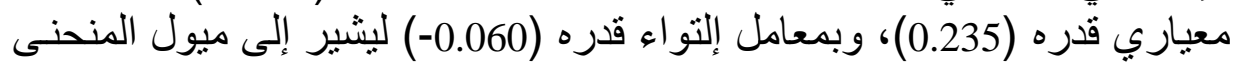

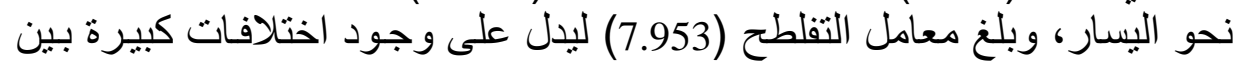

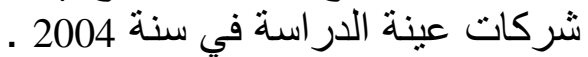
وبلغ المتوسط لأنموذج M.Jones من المستحقات المقدرة إلى إجمالي الموجودات

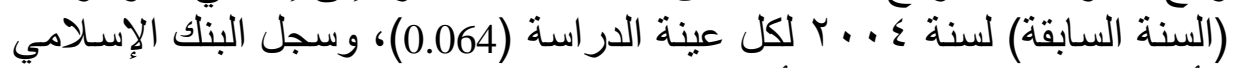

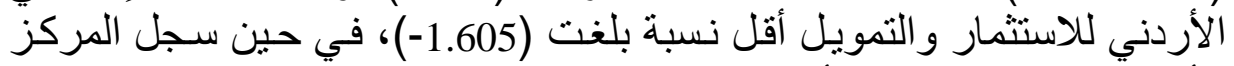

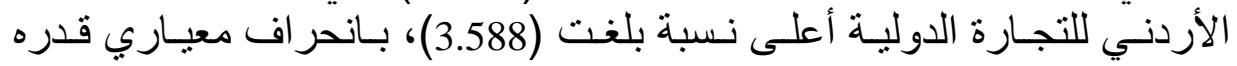

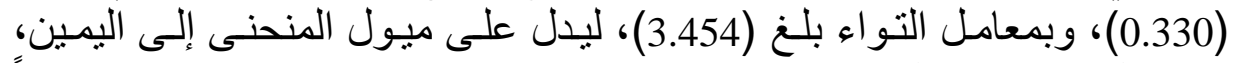

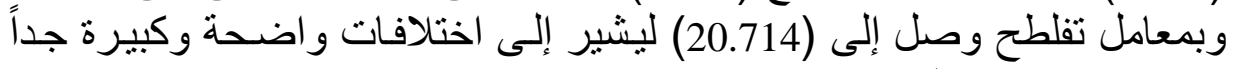

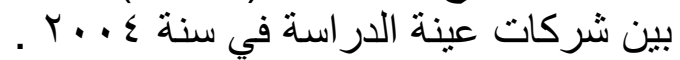

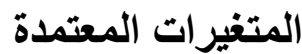

لغرض اختبار البيانات لتحقيق هدف الدراسة تم اعتمات اعتماد ثلاثة متغير ات معتمدة،

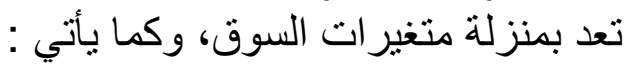


و ويقصد بـه سعر الإغلاق للسهم في السوق، ويعتمد على أساس سنوي للمدة من

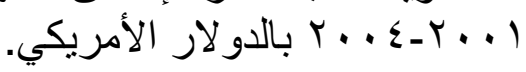

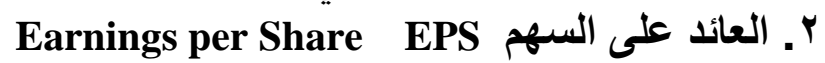

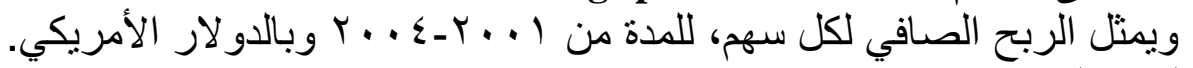

$$
\text { عائد السهم الواحد (EPS) = }=
$$

r. القيمة السوقية على عائد السهم الواحد Market Value on EPS

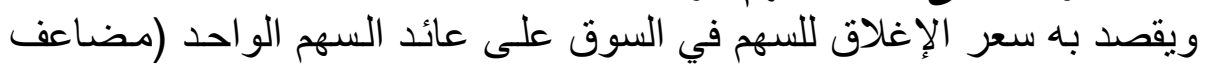

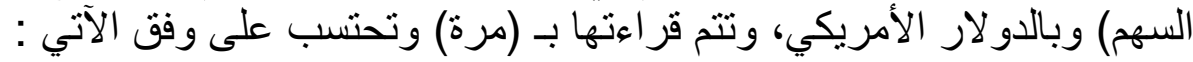

سعر إغلاق السهم

ثالثاً ـ مناقشة النتائج والاستنتاجات والتوصيات مناقشة نتائج تحليل الانحدار

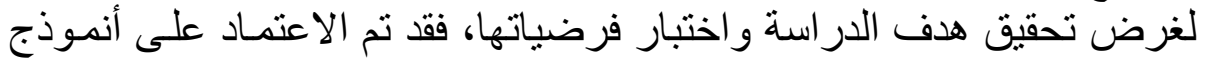

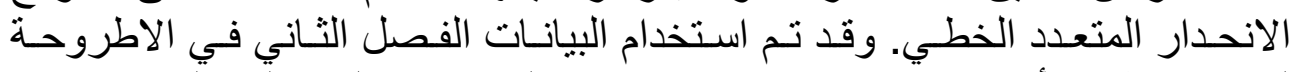

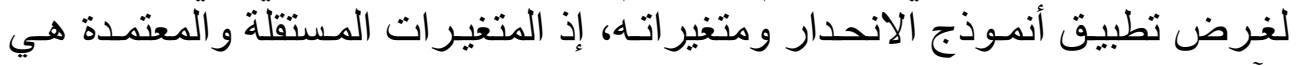

المتغيرات المستقلة

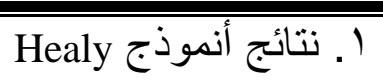

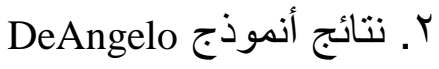

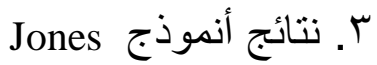

المتغيرات المعتمدة

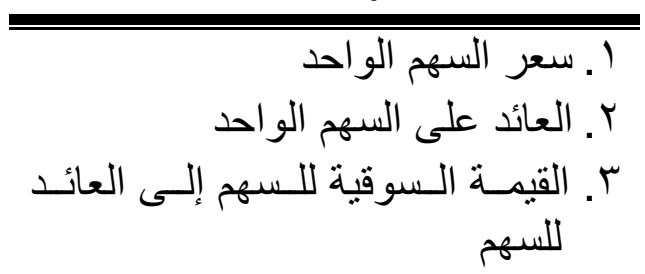

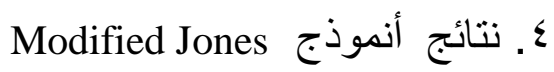
الآتي:

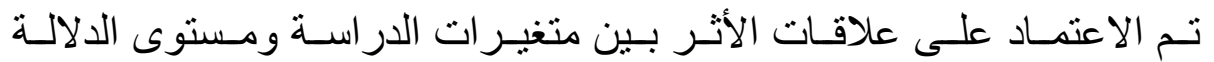

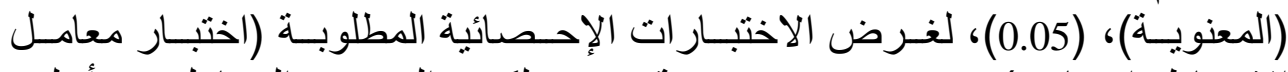

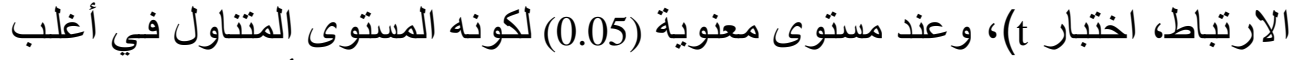

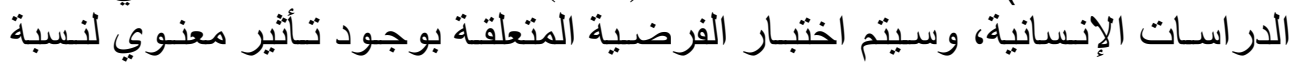

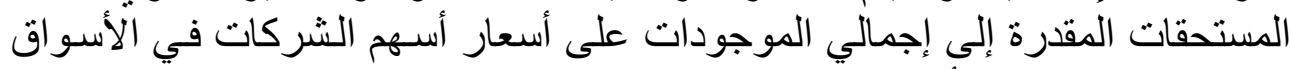

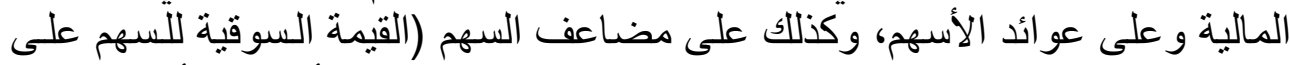

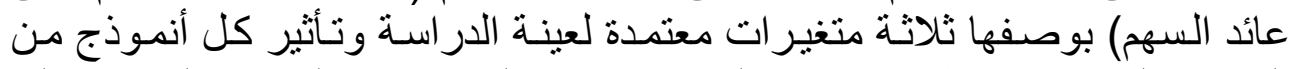

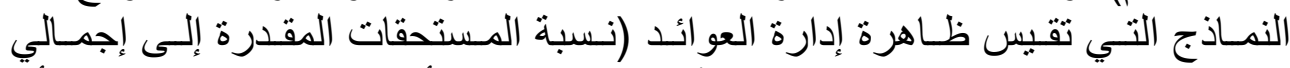

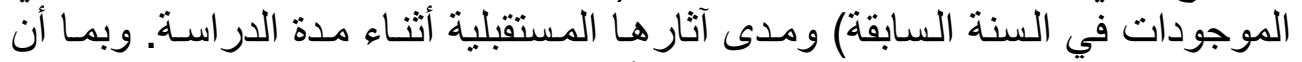

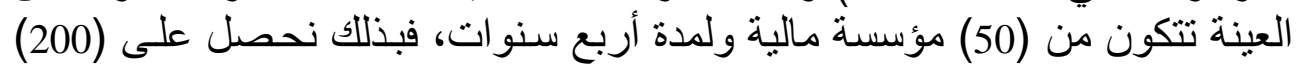




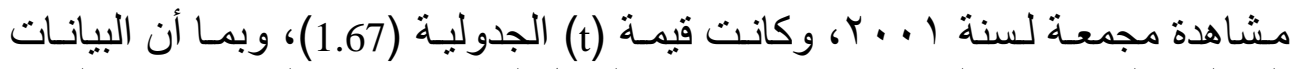

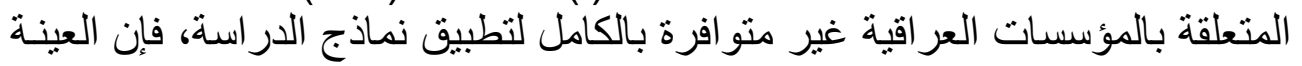

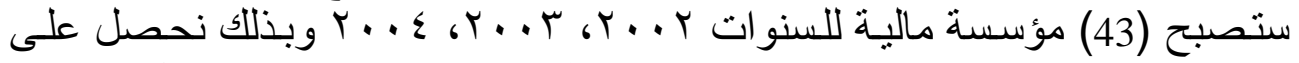

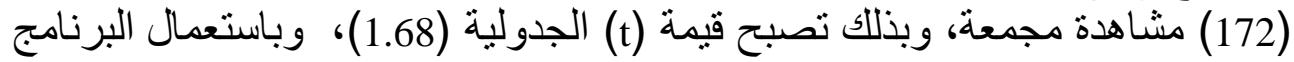

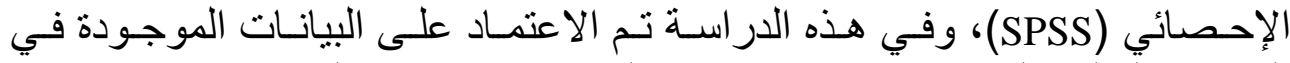

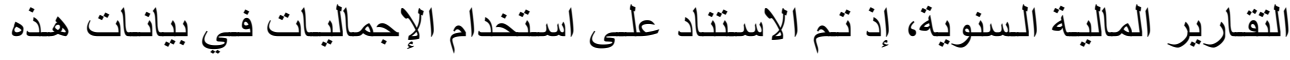

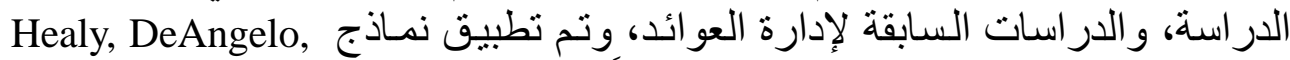
Jones, Modified Jones

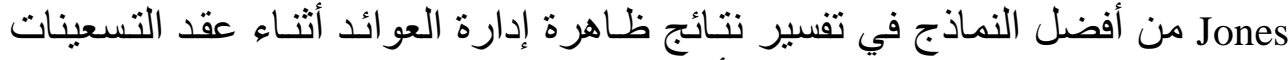

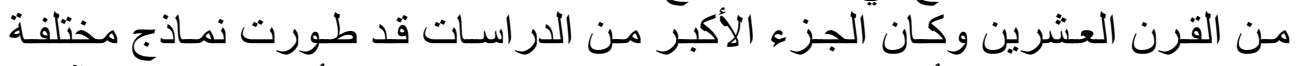
لاكتشاف إدارة العو ائد أو المستحقات غير الطنبير الطير الطية و علاقات التأثير تتمثل في الآتي:

تحليل علاقات تأثثر المتغيرات المستقلة (النماذج) في المتغير المعتمد (سعر السهم)

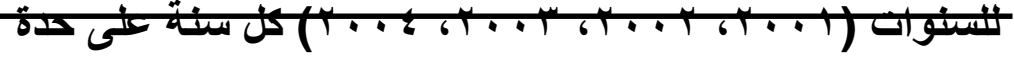

\section{- الجدول}

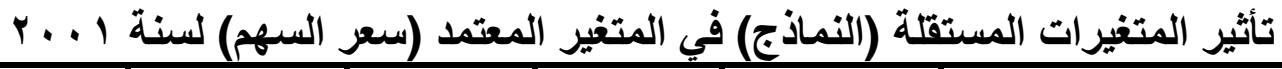

\begin{tabular}{|c|c|c|c|c|c|c|}
\hline التحديد & $\begin{array}{c}\text { أنموذج } \\
\text { Modified } \\
\text { Jones }\end{array}$ & أنموذج & $\begin{array}{l}\text { أنموذذج } \\
\text { Healy }\end{array}$ & ثابت معادلة & ستقلة & \\
\hline \multirow{2}{*}{0.307} & 1.022 & -0.110 & -0.934 & 19.725 & $\beta$ & \multirow{2}{*}{ عامل السعر } \\
\hline & 1.862 & -1.113 & -1.675 & 4.374 & $\mathrm{t}$ & \\
\hline
\end{tabular}

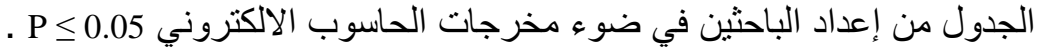

يظهر الجدول ه نتائج تحليل سنة ا . . ب و علاقة المتغيرات المستقلة بـالمتغير

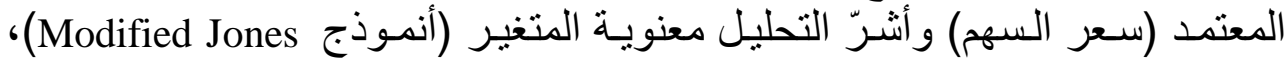

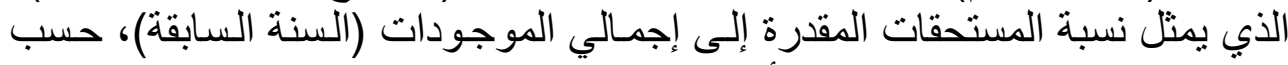

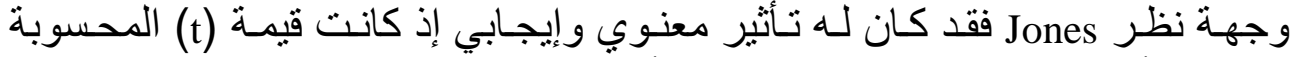

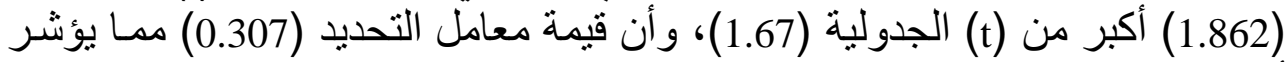

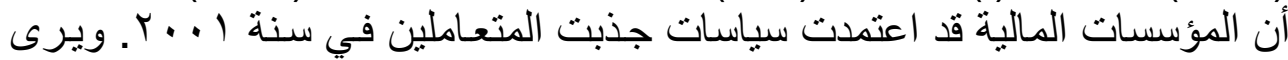


الباحثان أن هذه العلاقة جاءت بسبب قلة المعرفة و الدراية الكافية بالمعايير المحاسبية

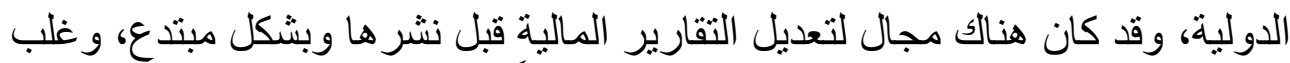

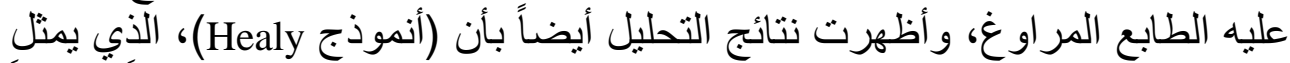

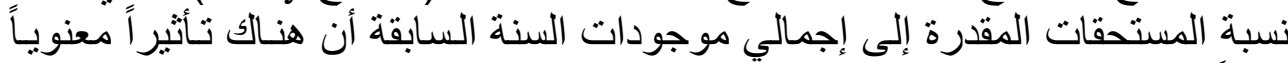

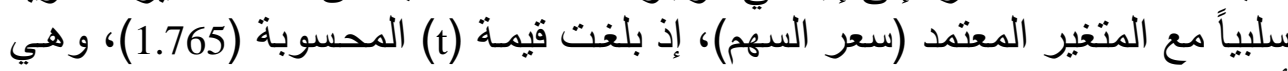
أكبر من قيمة (t) الجدولية (1.67).

\begin{tabular}{|c|c|c|c|c|c|c|c|}
\hline Y & ) لسنة r & (سعر أ) & خير المعتمد & ج) في الج & المستقلة () & لمسعير اد & \\
\hline $\begin{array}{c}\text { التحايل } \\
\text { Rعل } \\
\text { R }^{2}\end{array}$ & $\begin{array}{c}\text { أنموذج } \\
\text { Modified } \\
\text { Jones }\end{array}$ & $\begin{array}{l}\text { أنموذذج } \\
\text { Jones }\end{array}$ & $\begin{array}{c}\text { أنموذذج } \\
\text { DeAngelo }\end{array}$ & أنموذج & ثابت معادلة & & \\
\hline \multirow{2}{*}{0.368} & -0.145 & 0.361 & 2.004 & -2.062 & 22.455 & $\beta$ & \multirow{2}{*}{ عامل السعر } \\
\hline & -1.423 & 1.528 & 1.449 & -1.489 & 4.361 & $\mathrm{t}$ & \\
\hline
\end{tabular}

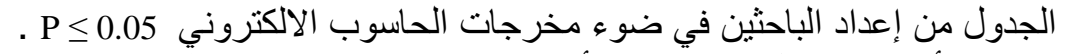

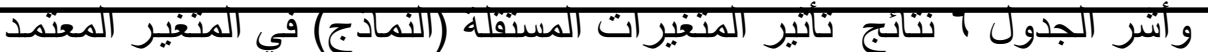

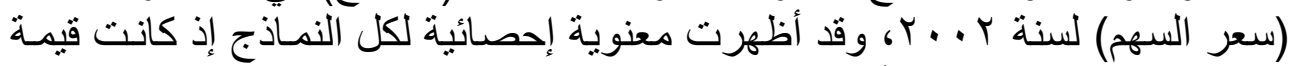
(t) لكل النماذج المحسوبة أقل من قيمة (t) الجدولية.

\begin{tabular}{|c|c|c|c|c|c|c|c|}
\hline$r$. & هم) لسنة & - سعر (سعر & المتغير المع Vول & 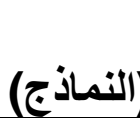 & لمستقلة & المتغير ات & تأتيّر \\
\hline التحديد Rعلم R & $\begin{array}{c}\text { أنموذج } \\
\text { Modified } \\
\text { Jones } \\
\end{array}$ & $\begin{array}{l}\text { أنموذذج } \\
\text { Jones }\end{array}$ & $\begin{array}{c}\text { أنموذج } \\
\text { DeAngelo }\end{array}$ & $\begin{array}{l}\text { أنموذذج } \\
\text { Healy }\end{array}$ & الانحدارلة & & \\
\hline \multirow{2}{*}{0.191} & -0.022 & 0.103 & 0.941 & -1.019 & 28.396 & $ß$ & \multirow{2}{*}{ عامل السعر } \\
\hline & -0.416 & 0.240 & 0.036 & -1.086 & 3.338 & $\mathrm{t}$ & \\
\hline \multicolumn{8}{|c|}{ الجدول من إعداد الباحثين في ضوء مخرجات الحاسوب الالكتروني P P P.05 . } \\
\hline \multicolumn{8}{|c|}{ 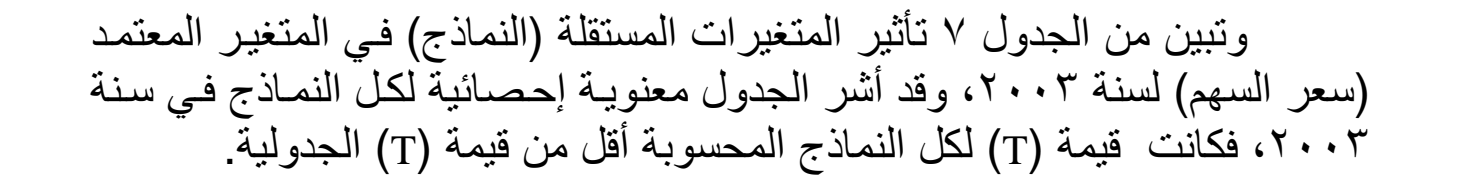 } \\
\hline
\end{tabular}

\section{الجدول}

تأثثير المتغيرات المستقلة (النماذج) في المتغير المعتمد (سعر السهم) لسنة ع . . ب 
الجميل والاوسكي [" ؛ ] إدارة العو ائد كمدخل لتعظيم قيمة المنظمة .

\begin{tabular}{|c|c|c|c|c|c|c|c|}
\hline $\begin{array}{c}\text { التحديد } \\
\text { Rع }^{2}\end{array}$ & $\begin{array}{c}\text { أنموذج } \\
\text { Modified } \\
\text { Jones }\end{array}$ & $\begin{array}{l}\text { أنموذج } \\
\text { Jones }\end{array}$ & $\begin{array}{c}\text { أنموذذج } \\
\text { DeAngelo }\end{array}$ & أنموذج & ثابت معادلة & ت & \\
\hline \multirow{2}{*}{0.250} & -0.032 & 0.189 & 3.759 & -3.760 & 55.587 & $\beta$ & \multirow{2}{*}{ عامل السعر } \\
\hline & 0.259 & 0.520 & 1.389 & -1.403 & 3.832 & $t$ & \\
\hline
\end{tabular}

يتضح من الجدول ^، تأثير المتغيرات المستقلة (النماذج) على المتغير المعتمد إنها

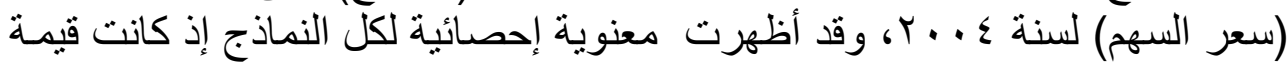
(t) لكل النماذج المحسوبة أقل من قيمة (t) الجدولية.

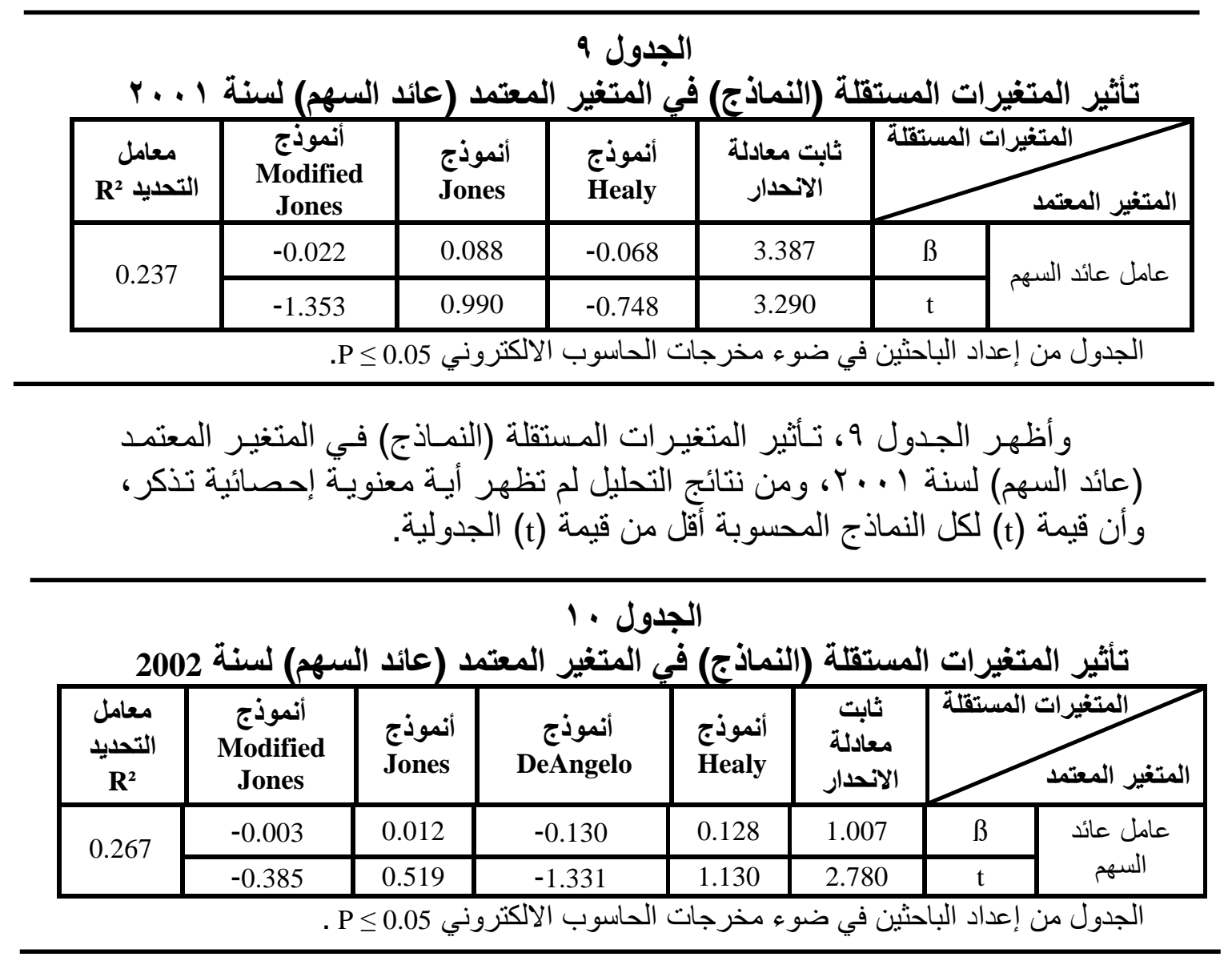


و عرض الجدول • (، تأثثر المتغيرات المستقلة (النمـاذج) في المتغير المعتمد

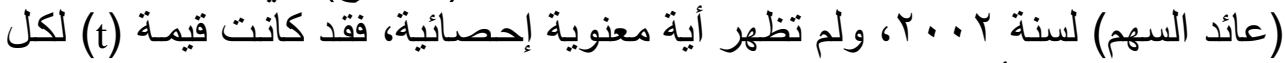

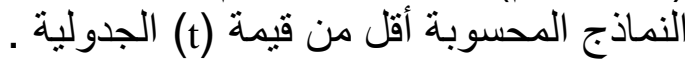

\section{الجدول الجما 11}

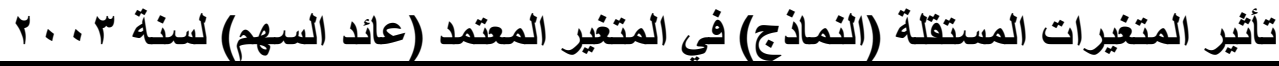

\begin{tabular}{|c|c|c|c|c|c|c|c|}
\hline التحديد Rعل & $\begin{array}{c}\text { أنموذج } \\
\text { Modified } \\
\text { Jones }\end{array}$ & أنموذج & $\begin{array}{c}\text { أنموذج } \\
\text { DeAngelo }\end{array}$ & أنموذج & معادلة & & \\
\hline \multirow{2}{*}{0.190} & 0.001 & 0.010 & 0.046 & -0.053 & 1.407 & $\beta$ & \multirow{2}{*}{ عامل عائد } \\
\hline & -0.311 & 0.377 & 0.983 & -1.106 & 3.240 & $\mathrm{t}$ & \\
\hline
\end{tabular}

الجدول من إعداد الباحثين في ضو ع مخرجات الحاسوب الالكتروني

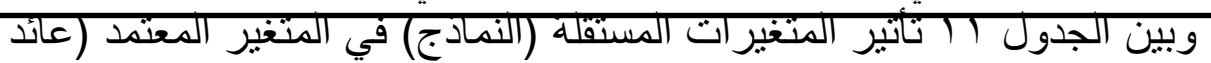

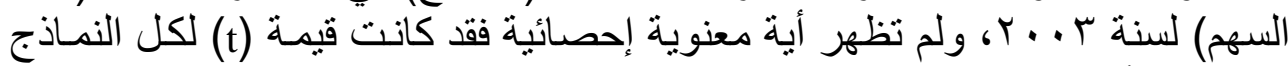

المحسوبة أقل من قيمة (t) الجدولية.

\begin{tabular}{|c|c|c|c|c|c|c|c|}
\hline & ائد السههم) & لمعتمد & ع) في المث & لمقة (الة & يرات ال & تأثير الم & \\
\hline التحديد Rعل & $\begin{array}{c}\text { أنموذج } \\
\text { Modified } \\
\text { Jones }\end{array}$ & $\begin{array}{l}\text { أنموذج } \\
\text { Jones }\end{array}$ & $\begin{array}{c}\text { أنموذذج } \\
\text { DeAngelo }\end{array}$ & أنموذج & ثماثبتة & & \\
\hline \multirow{2}{*}{0.210} & 0.004 & 0.011 & 0.072 & -0.079 & 2.027 & $\beta$ & \multirow{2}{*}{ عامل عائد } \\
\hline & 0.708 & 0.780 & 0.680 & -0.753 & 3.590 & $t$ & \\
\hline
\end{tabular}

الجدول من إعداد الباحثين في ضوء مخرجات الحاسوب الالكتروني

وبين الجدول r ا تأثير المتغيرات المستقلة (النماذج) في المتغير المعتمد (عائد

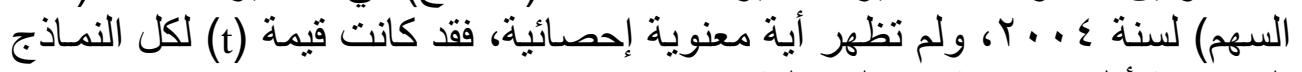
المحسوبة أقل من قيمة (t) الجدولية.

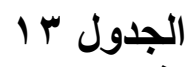

تأثير المتغيرات المستقلة (النماذج) في المتغير المعتمد (القيمة السوقية إلى العائد

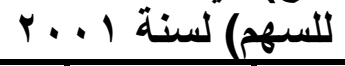

\begin{tabular}{|c|c|c|c|c|c|}
\hline التحديد معامل & $\begin{array}{c}\text { أنموذذج } \\
\text { Modified } \\
\text { Jones }\end{array}$ & $\begin{array}{l}\text { أنموذج } \\
\text { Jones }\end{array}$ & أنموذج & ثابت معادلة & لـ المتغيرات المستقلة \\
\hline
\end{tabular}




\begin{tabular}{|c|c|c|c|c|c|c|}
\hline \multirow{2}{*}{0.150} & -0.135 & -3.114 & 3.230 & 27.296 & ß & \multirow{2}{*}{ عامل مضاعف } \\
\hline & -0.352 & -1.474 & 1.504 & 1.572 & $\mathrm{t}$ & \\
\hline
\end{tabular}

الجدول من إعداد الباحثين في ضوء مخرجات الحاسوب الالكتروني P

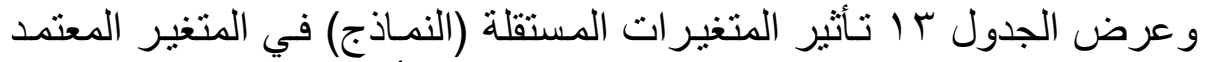

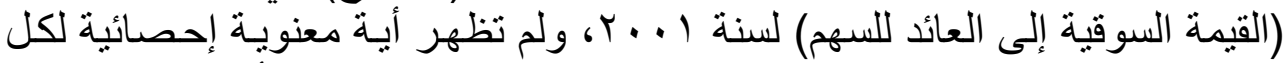

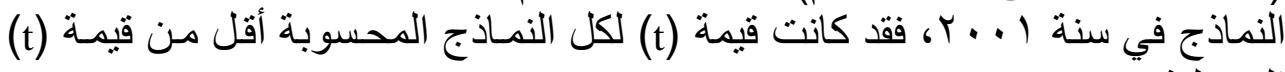

الجدولية.

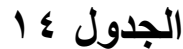

تأثير المتغيرات المستقلة (النماذج) في المتغير المعتمد (القيمة السوقية إلى العائد

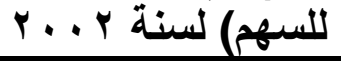

\begin{tabular}{|c|c|c|c|c|c|c|c|}
\hline التحديد Rعل & $\begin{array}{c}\text { أنموذج } \\
\text { Modified } \\
\text { Jones }\end{array}$ & $\begin{array}{l}\text { أنموذج } \\
\text { Jones }\end{array}$ & أنموذجج & $\begin{array}{l}\text { أنموذج } \\
\text { Healy }\end{array}$ & الانحدارلة & & \\
\hline \multirow{2}{*}{0.150} & 0.619 & -1.346 & -1.288 & 1.491 & 42.141 & $\beta$ & \multirow{2}{*}{ مضاعف } \\
\hline & 0.884 & -0.380 & -0.136 & 0.157 & 1.194 & $\mathrm{t}$ & \\
\hline
\end{tabular}

الجدول من إعداد الباحثين في ضوء مخرجات الحاسوب الالكتروني P 0.05.

يبين الجدول ـ ا تأثير المتغير ات المستقلة (النماذج) في المتغير المعتمد (القيمة

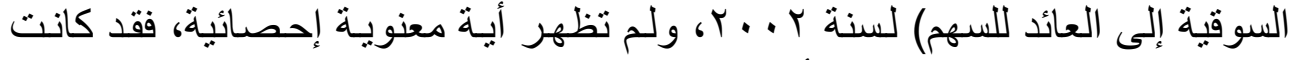
قيمة (t) لكل النماذج المحسوبة أقل من قيمة (t) الجدولية.

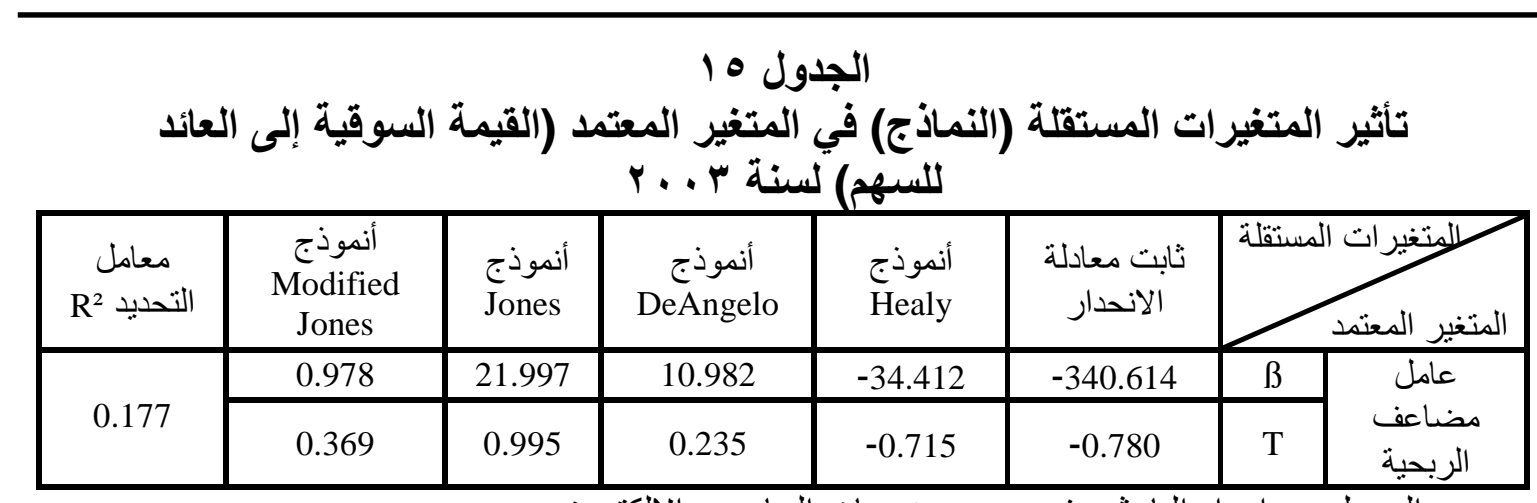

الجدول من إعداد الباحثين في ضوء مخرجات الحاسوب الالكتروني P 
وأظهر الجدول 1 نأثثر المتغيرات المستقلة (النمـاذج) في المتغير المعتمد إنها

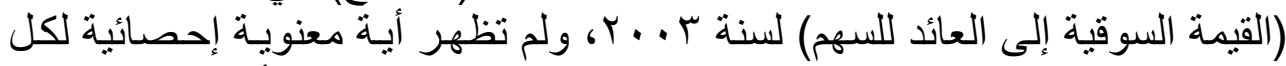

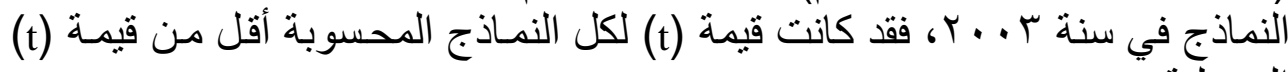
الجدولية.

\section{الجدول 17}

تأثثير المتغيرات المستقلة (النماذج) في المتغير المعتمد (القيمة السوقية إلى العائد

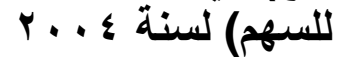

\begin{tabular}{|c|c|c|c|c|c|c|c|}
\hline التحديد Rعل & $\begin{array}{c}\text { أنموذج } \\
\text { Modified } \\
\text { Jones }\end{array}$ & $\begin{array}{l}\text { أنموذج } \\
\text { Jones }\end{array}$ & $\begin{array}{c}\text { أنموذج } \\
\text { DeAngelo }\end{array}$ & أنموذج & ثلاثلة & & \\
\hline \multirow{2}{*}{0.551} & -0.114 & -0.295 & 1.494 & 1.067 & 24.182 & $\beta$ & \multirow{2}{*}{ مضاعف } \\
\hline & -3.783 & -3.301 & 2.247 & -1.620 & 6.789 & $\mathrm{t}$ & \\
\hline
\end{tabular}

الجدول من إعداد الباحثين في ضوء مخرجات الحاسوب الالكتروني

وبينت نتائج التحليل في الجدول 17 أتأثير المتغير ات المستقلة (النمـاذج) خلال

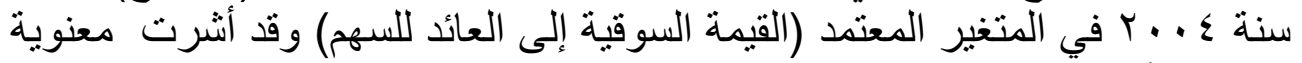
المتغير (أنموذج Modified Jones)، الذي يمثل نسبة المستحقات المقدرة إلى إجمالي

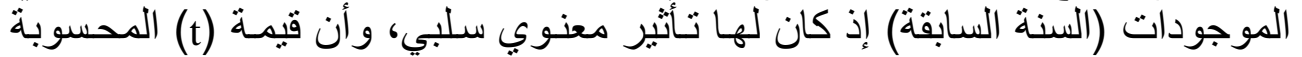

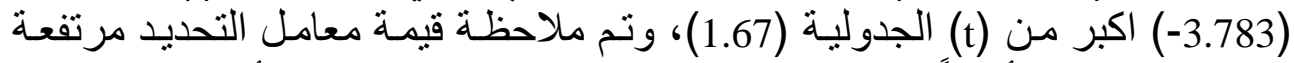

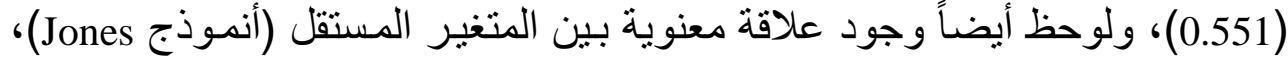

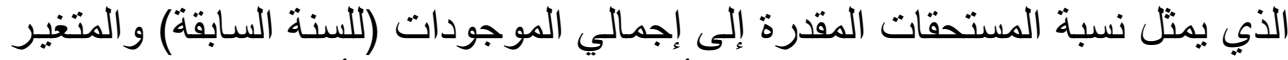

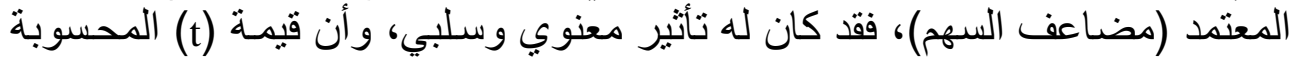

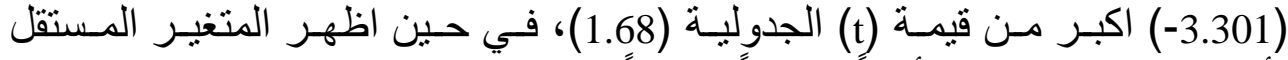

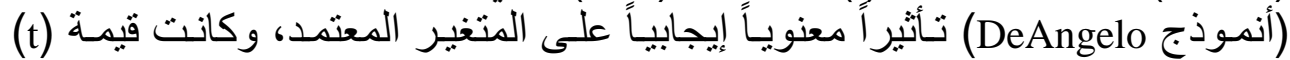

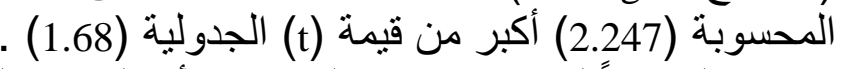

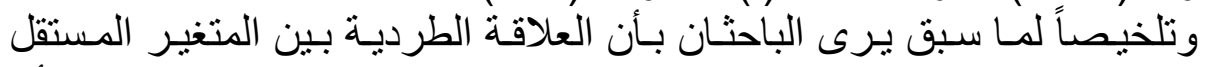

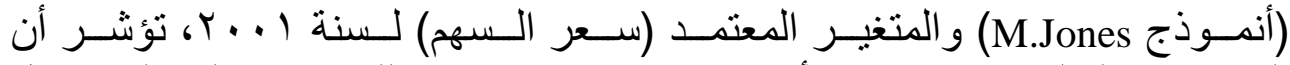
المؤسسات المالية قد استطاعت أن تزيد من ما هو مستحق للمؤسسة على المى الغير قبل

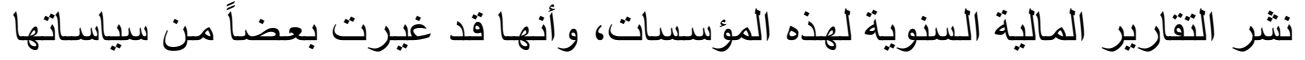




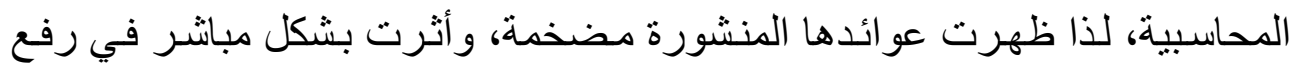

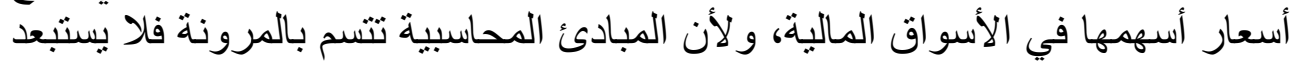

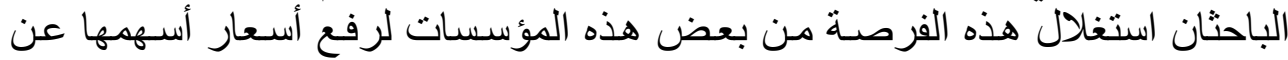

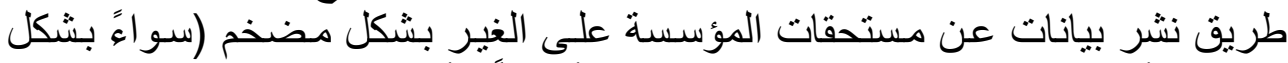

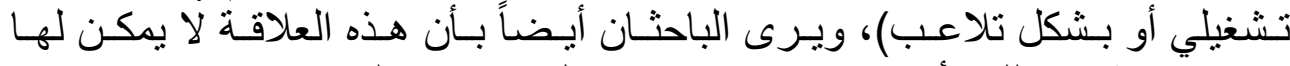

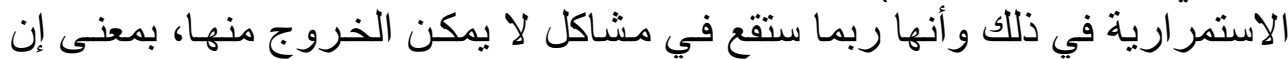

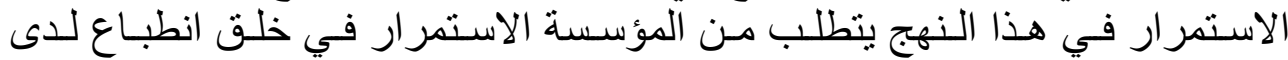

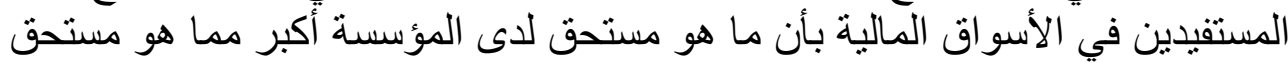

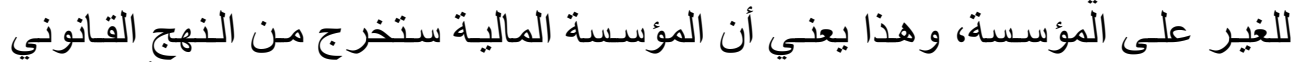

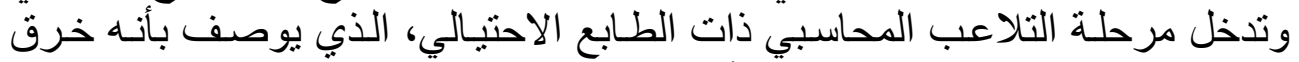

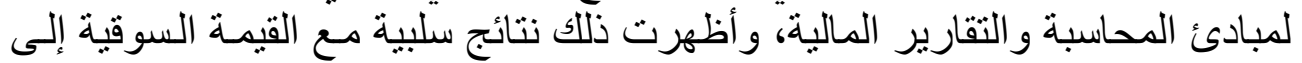

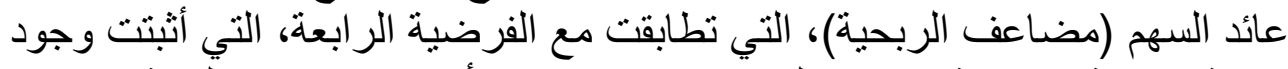

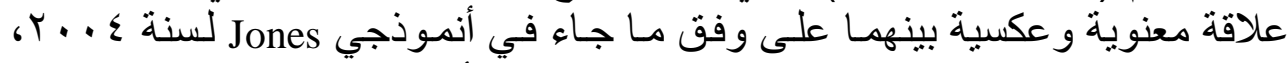
وقد تطابق هذا مع نتائج عدد من الدراسات التي تؤكد أن هناك نتائج سلبية من عملية

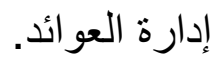

اتضح مما تقام في الدراسة أن هناك نو عين من الاستنتاجات هما:

| - الاستنتاجات

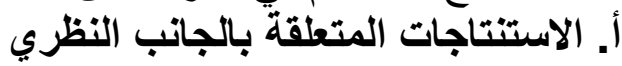

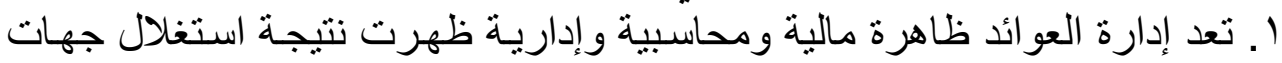

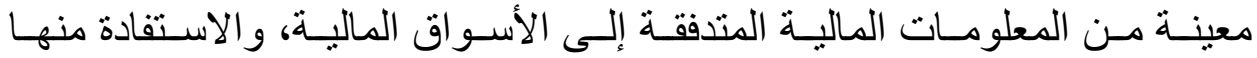

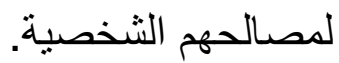

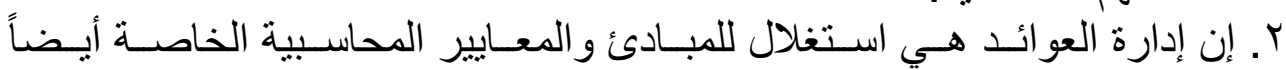

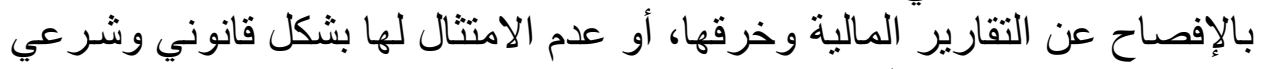
وبما يضخم من قيمتها السوقية.

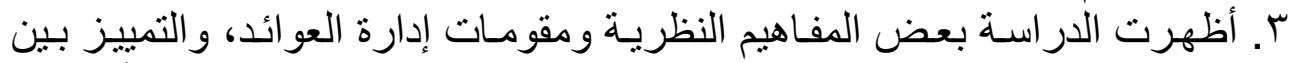

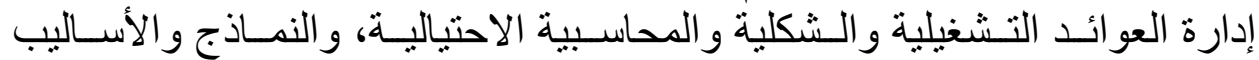

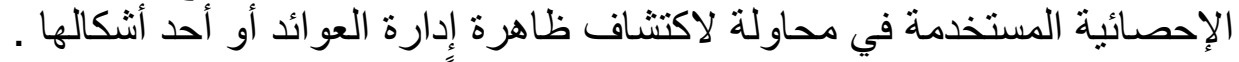

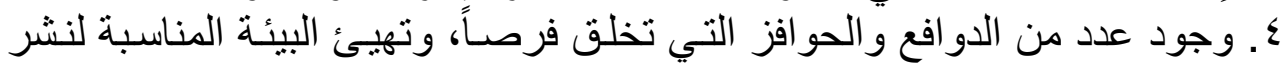

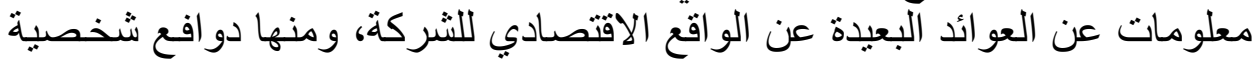

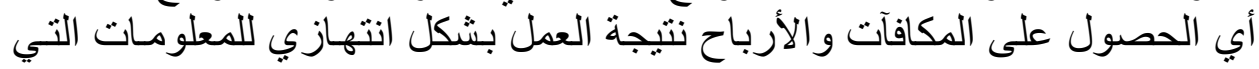

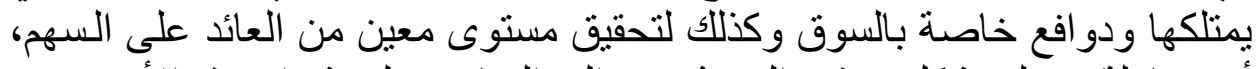

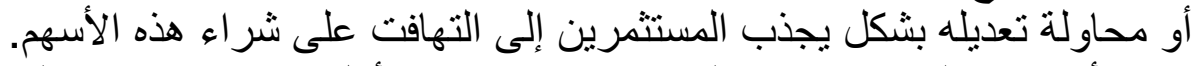

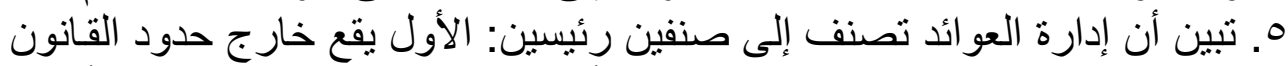

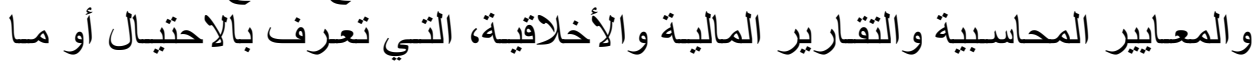

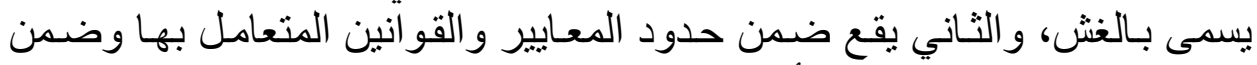

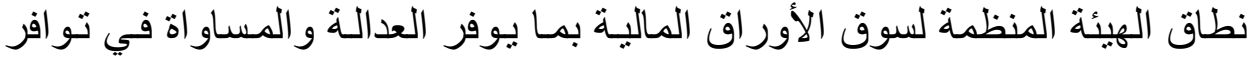




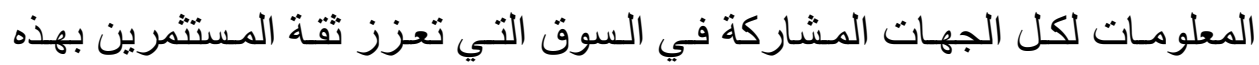

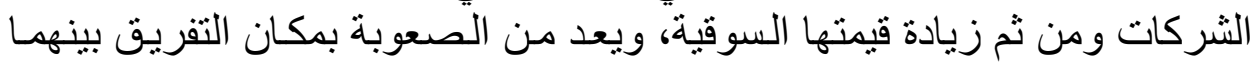

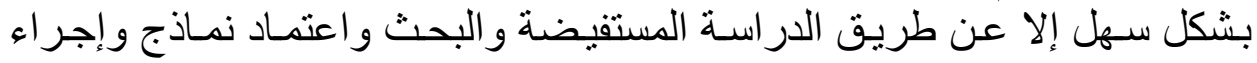
اختبار ات إحصائية.

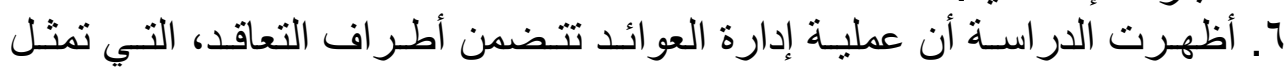

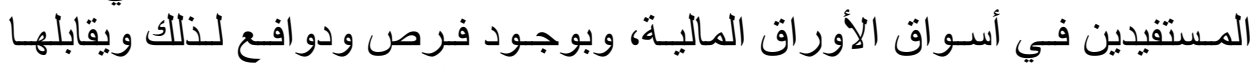

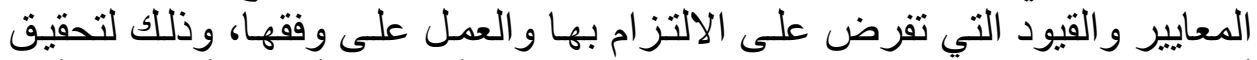

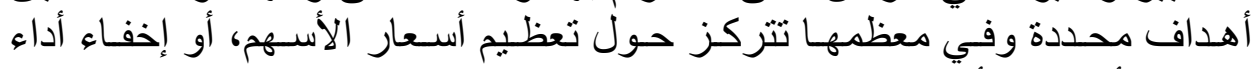
متدهور أو إبراز أداء قدوي معدي.

\section{ب. الاستتناجات المتعلقة بالجانب التطبيقي}

لقد توصل الباحثان من نتائج التحليل إلى مجمو عة رئيسة لأبئية من الاستنتاجات التي يمكن تلخيصها ما يأني:

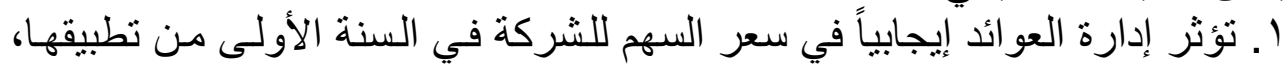

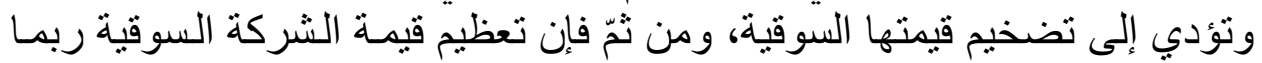

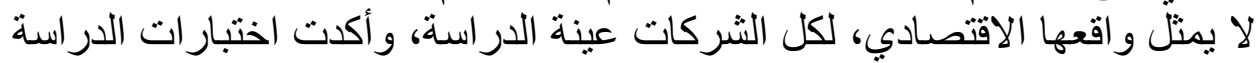

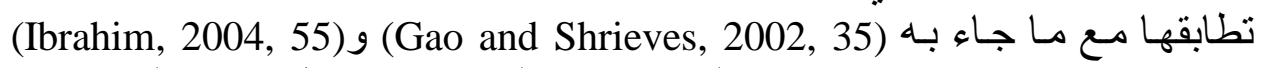
و(Chan, 1999, 78)، في در استهم لقياس إدارة العو ائد من خلال نماذج المستحقات

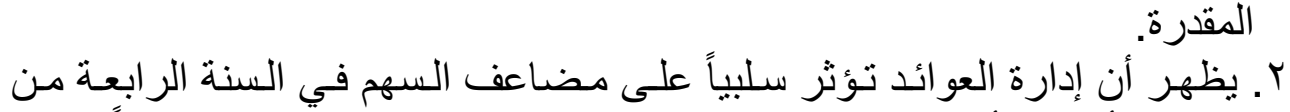

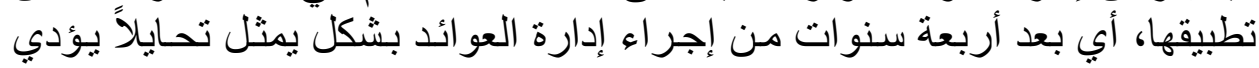

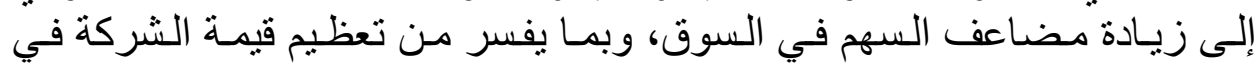
السوق في كل العينة. r. أثتتت الدر اسة أنه لا توجد علاقة معنوية بين إدارة العو ائد و عائد السهم الواحد في

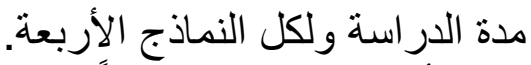

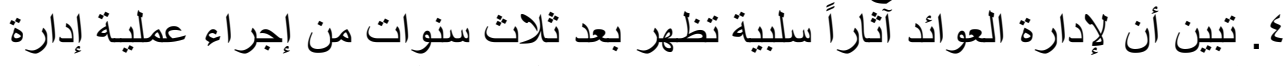

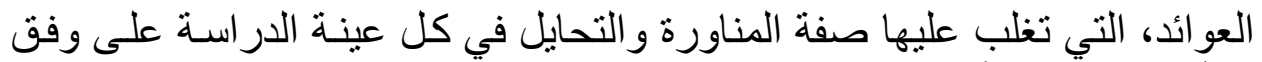

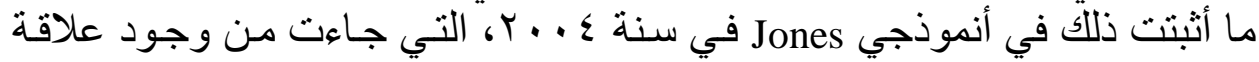

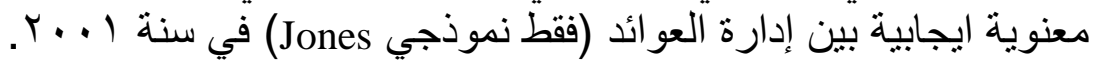

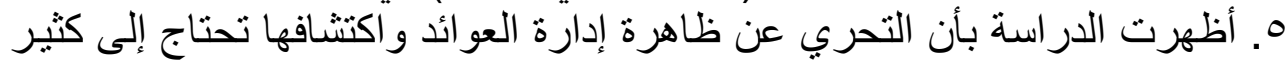

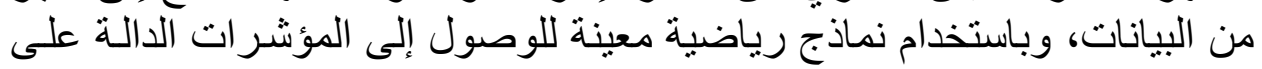

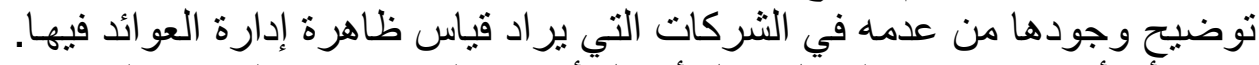

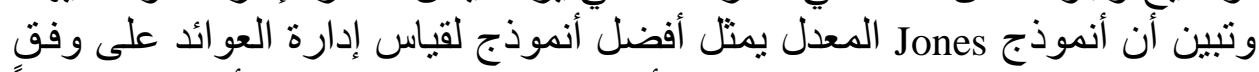

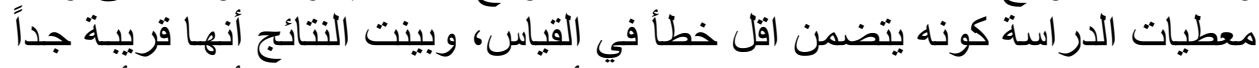

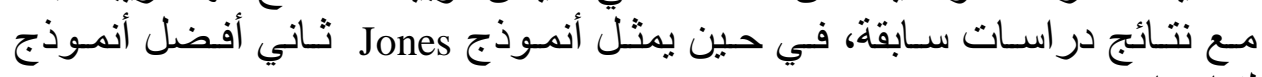




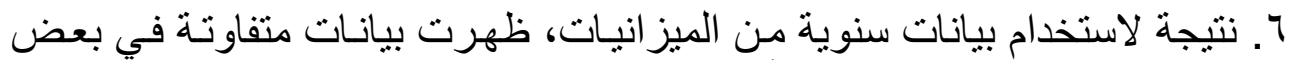

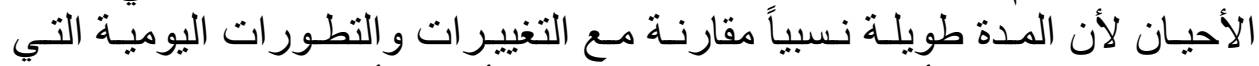

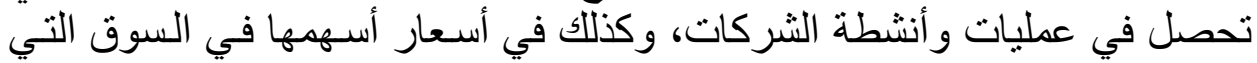
تؤُثر في قيمتها السوقية نتيجة لذلك.

\section{ثثانياً التوصيات}

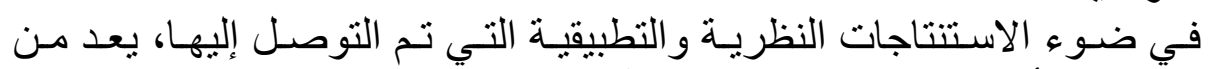
الأهمية بمكان الأخذ بالاعتبار التوصيات الآتية:

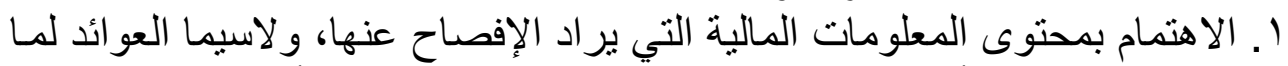

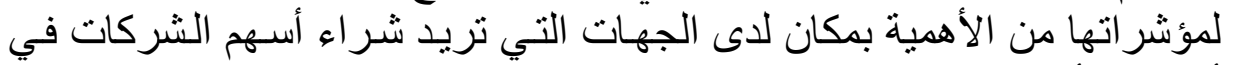
أسواق الأوراق المالية.

r. لا بد من إجر اء تحليل أولي، وتحديد دقيق لمؤشر السهم المر غوب الاستثمار فيـه

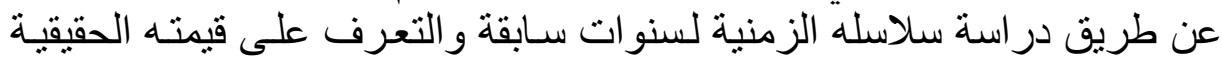

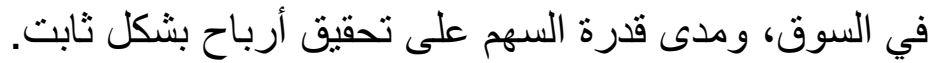

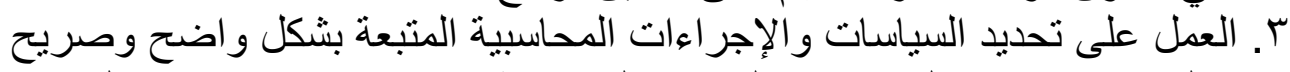

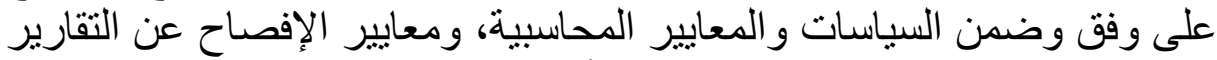

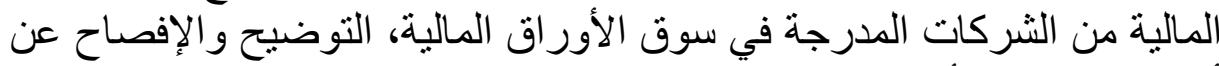

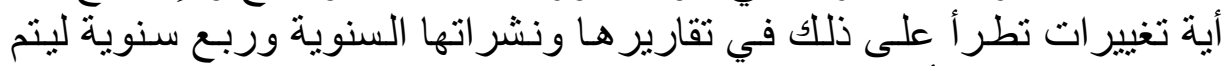

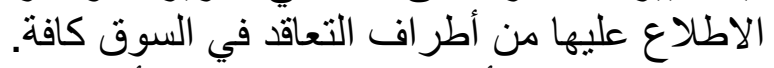

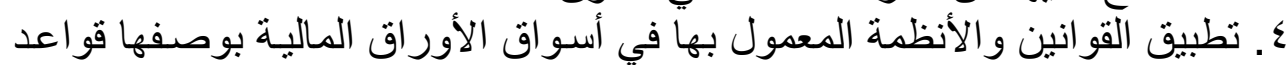

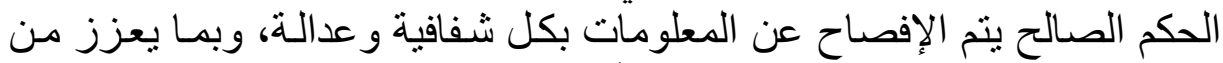

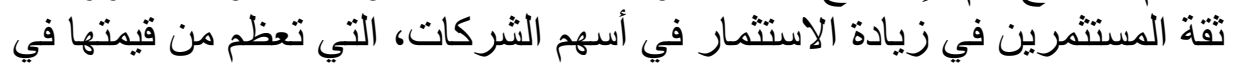

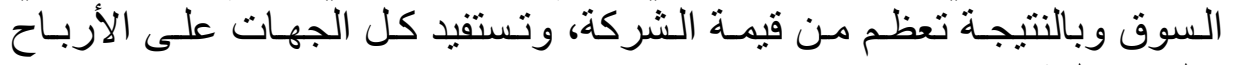
و الفو ائد الكثيرة.

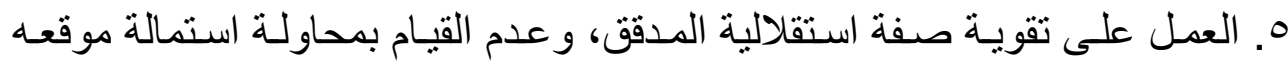

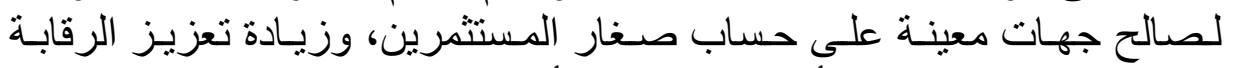

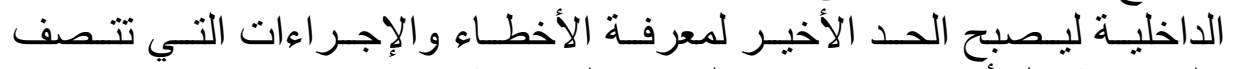

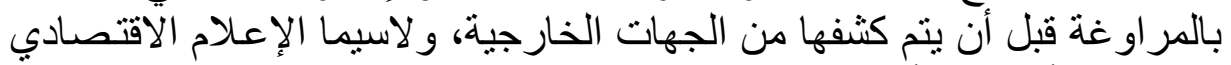
الذي يتابع أسواق الأوراق المالية، التي تمثل جهة رقاب التهابية بشكل كبير. 


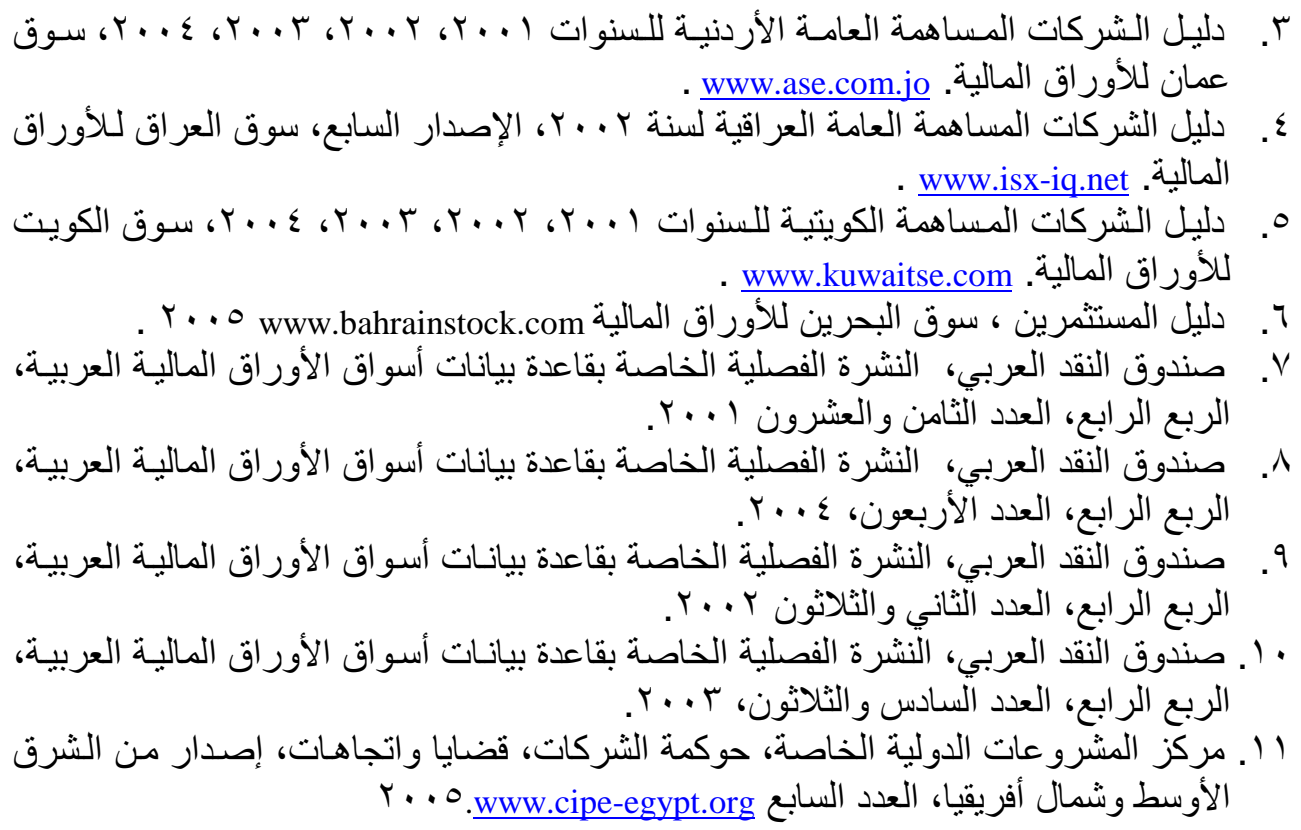

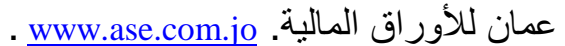

\section{ثانياً- المراجع باللغة الأجنبية}

1. Abdelghany Khaled Elmoatasem, measuring the quality of earnings, managerial auditing journal, vol.20, no.9, Emerald group publishing limited, http://www.emeraldinsight.com/0268-6902.htm.2005.

2. Beneish Messod D., the detection of earnings manipulation, Financial Analysts' Journal, 55(5), 1999.

3. Burgstahler David, Luzi Hail, \& Christia Leuz, the importance of reporting incentives: earnings management in European private \& public firms, the Wharto Financial Institutions Center. 2001

4. Chen Shaw, Bing-Xuan Lin, Yaping Wang, \& Liansheng, Detecting the frequency \& magnitude of earnings management: a parametric model \& empirical analysis, college of business administration, university of Rhode Island, working paper series N.6. 2005.

5. Clikeman Paul M., where Auditors fear to tread, http://www.theiia.org/iia/indx.cfm?doc id=4338. 2003.

6. Clikeman Paul M., Marshall A.Geiger, \& Brendan T.O'connell, Student perceptions of earnings management, the effects of national origin \& gender, E. Claiborne Robins School of business, university of Richmond, working paper.2000.

7. Culvenor Jane, Godfrey Jayne M., \& Byrne Graeme, Modeling total accruals in an international environment: the impact of alternative measures of PPE, the American accounting association, annual meeting, USA, 1998. .

8. Dechow Patricia M., Richard G.Sloan, \& Amy P.Sweeney, detecting earnings management, the accounting review, published by American Accounting Association vol. 70, N.2, 1995 , USA.

9. Dillard Jesse F. \& Macintosh Norman B., Modes of management accounting \& control systems: astructratist \& poststruratist sociological problematic. http://les.man.ac.uk/ipa/ papers/41.pdf , 1999. 


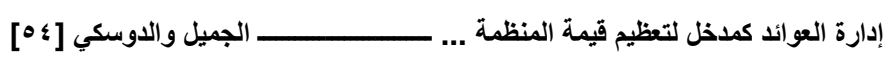

10. Graham John R., Harvey Gampbell R., \& Rajgopal Shiva, the economics implications of corporate financial reporting, http://faculty.fuqua.duke.edu/ charvey/Research/Davos.ppt.2005.

11. Gao Pengjie, \& R. E. Shrieves, earnings management \& executive compensation: a case of overdose of option \& under dose of salary, http://papers.ssrn.com/sol3/papers.cfm?abstract_id=302843.2002.

12. Healy P.M, the effect of bonus schemes on accounting decisions, Journal of Accounting \& Economics, 7. 1985, USA.

13. Healy, P.M, \& J.M. Wahlen,. A review of the earnings management literature \& its implications for standard setting. Accounting Horizons, Vol 13 (Number 4), 1999.

14. Jiang, J, S., SESSION ONE, Financial Numbers Game \& Earnings Management, 2005.

15. Kimbro Marinilka Barros, Managing under pricing: the case of pre-IPO discretionary accruals in china, Journal of international financial management \& accounting, volume 16, issue 3, USA, 2005.

16. Kinnunen Juha, \& Koskela Markku, Who is Miss World in Cosmetic Earnings Management?, an analysis of small upward rounding of net income numbers among 18 countries, Helsinki School of Economics, University of Helsinki, Helsinki,2002.

17. Kothari S.P., Capital markets research in accounting, journal of accounting \& economics, V. 31, www.elsevier.com/ econbase.2001.

18. Lee Chi-Wen Jevons, Yue Li, \& Heng Yue, performance, Growth, \& Earnings Management. http://www0.gsb.columbia.edu/ rast/Yue\%20Li.pdf , 2005.

19. McNichols, M. Research Design Issues in Earnings Management Studies, Journal of Accounting \& Public Policy, Vol. 19, No. 4-5,2000.

20. Millstein Ira, When earnings management becomes cooking the books, www.ft.com, Financial times.2005.

21. Saidi Nasser, The Second Middle east \& North Africa Regional Corporate Governance Forum, Corporate Governance in MENA Countries Improving Transparency \& Disclosure, Beirut, LEBANON. www.TranspapncyLebanon.org.2004.

22. Schipper K. , Commentary on Earnings Management, Accounting Horizons, 91102. USA 1989.

23. Shireen jit kaur joh, christane A.jubb, \&, Keith A. Houghton, Ethics \& Auditing, Australian national university, 2005.

24. Sidney Davidson, Clyde Strickney, \& Roman Weil, the language of business, accounting, Thomson, Horton \& Daughters, Sun Lakes, Arizona, USA, 1986.

25. Sloan R, G., do stock price fully reflect information in accruals \& cash flows about future earnings? the Accounting Review 71.1996.

26. Stephen, D.M., Pervaiz, A., \& Michael, A.P., Earnings Management, When Does Juggling the Numbers Become Fraud, Article form Http://www.cfenet.com.search.2000.

27. Stolowy Herve \& Gaetan Breton, Accounts Manipulation: A Literature Review \& Proposed Conceptual Framework, eight draft, http://campus.hec.fr/profs/stolowy/perso/Articles/RAF2003.pdf , 2003.

28. Van Caneghem, T., earnings management induced by reference points, British accounting review vol. $34,2002$.

29. Stolowy Herve, \& Geatan Breton, a Review of Research on Accounts Manipulation, For Presentation at the 23rd Annual Congress of the EUROPEAN ACCOUNTING ASSOCIATION, 2000. 
30. Whelan Catherine J., \& McNamara Raymond P., the impact of earnings management on the value-relevance of earnings \& book value: A Comparison of Short-Term \& Long-Term Discretionary Accruals 2004.

31. Woods Ron, Financial Accounting, http://northonline. northseattle.edu/rwoods/ch6EarningsManagement.htm. North Seattle Community, USA 2004.

32. Worthy Ford S., Manipulating Profits: How It's Done, Fortune Magazine, USA, 1994.

33. Xie, B., Davidson, W.N., \& Dedalt, P.J , earnings management \& corporate governance: the role of the board \& the audit committee, journal of corporate finance, volume.9, number.3.2003.

34. Young, S. , Systematic Measurement Error in the Estimation of Discretionary Accruals: an Evaluation of Alternative Modeling Procedures, Journal of Business Finance \& Accounting, Vol. 26,1999.

35. Zhang Huai, Detecting earnings management- evidence from Rounding-up in reported EPS, department of accounting, college of business administration university of Illinois at Chicago, USA, 2002.

36. Zhang Yan, Donald R.Deis, Pinghsun Huang, \& Jacquelyn Sue Moffitt, Earnings Smoothing Choice, Firm Value \& Corporate Monitoring, 2004.

37. Comiskey Eugene, \& Charles W. Mulford, the Financial Numbers Game: Detecting Creative Accounting Practices, Published By John Wily \& Sons, USA, 2002 .

38. Comiskey Eugene, Mulford Charles W., financial warnings, john wiley \& sons, New York, USA, 1996.

39. Dechow Patricia M., \& Douglas J.Skinner, Earnings Management: Reconciling the Views of Accounting Academics, Practitioners \& Regulators, University of Michigan Business School, Accounting Horizons, n. 14, pp. 235-250.presented \& discussed at 1999 AAA/FASB Financial Reporting Issues Conference, USA, 2000.

40. McKee, E. Thomas, Earnings Management: an executive management, SouthWestern Educational. USA, 2005 .

41. Stolowy Herve, \& Lebas Michel J., Corporate Financial Reporting: a global perspective , 2002.

42. Ibrahim s.Salma, An Alternative measure to Detect Intentional Earnings Management through Discretionary Accruals, PHD thesis in business administration, to the Faculty of the Graduate School of the University of Maryland, College Park, USA. 2005. 